\title{
Retrofitting of a listed brick and wood building using vacuum insulation panels on the exterior of the facade: measurements and simulations
}

Pär Johansson

Carl-Eric Hagentoft

Angela Sasic Kalagasidis

Department of Civil and Environmental Engineering

Chalmers University of Technology

SE-412 96, Gothenburg

SWEDEN

Corresponding author: Pär Johansson

Direct dial: +46 317721966

Fax: +46 317721993

par.johansson@chalmers.se; par.joh@gmail.com

\begin{abstract}
Many old listed buildings have an unsatisfactory thermal performance compared to the standards of today. The listing often limits the position and necessary thickness of an added insulation layer in the building envelope. Vacuum insulation panels (VIP) present unprecedented possibilities to reduce the required thickness of the insulation layer. The aim of this study is to explore the performance of VIP in the retrofitting of listed buildings. The goal is to improve the thermal transmittance and moisture performance of the wall and the thermal comfort for the occupants. Hygrothermal sensors were installed in the wall of a listed building insulated with VIP on the exterior. Sensors were also installed in a neighboring (nonretrofitted) wall as reference. Through a comparative analysis of the measured data it was concluded that the hygrothermal performance of the retrofitted wall was substantially better than of the reference wall. The measurement results were also compared to hygrothermal simulations to quantify the improvements in the thermal transmittance and moisture performance. A deviation was found between the measured and simulated relative humidity in the wall which was explained by vertical air leakage paths in the wall.
\end{abstract}


Preprint version, Energy and Buildings, Available online 21 January 2014

http://dx.doi.org/10.1016/j.enbuild.2014.01.019

\section{Keywords}

listed building; retrofit; brick; wood; vacuum insulation panel; measurement; simulation; hygrothermal performance; thermal transmittance; thermal comfort

\section{Introduction}

Old buildings are often protected for their aesthetical and historical contribution to the society. Around $10 \%$ of the 3100000 Swedish buildings are considered to have some preservation value. Although the total number of specified listed buildings in Sweden is uncertain, an investigation in 8 Swedish counties in 2010 showed that it can be roughly approximated to 67 000 buildings or about 2\% of the Swedish building stock. To that number around 2600 buildings are added every year [1]. Many of these listed buildings have a low thermal performance of the building envelope compared to the standards of today, leading to a high energy use for heating and an insufficient thermal comfort for the occupants. It is a challenge to increase the thermal performance while maintaining the qualities of the buildings and historical areas of interest.

According to a study by the Swedish National Board of Housing, Building and Planning [2], approximately $31 \%$ of the Swedish multi-family buildings are suitable for a façade retrofitting. Because of technical or preservation reasons, $41 \%$ of the buildings are not considered suitable while the remaining $28 \%$ are dubious. Depending on whether the thermal insulation is placed on the interior or exterior of the existing structure, different hygrothermal conditions are yielded in the construction. From a building physics perspective, exterior insulation of heavy-weight buildings is to be preferred because it keeps the heavy wall elements temperate and dry, and it is more effective against thermal bridges than the interior insulation. In case of interior insulation, some treatment of the exterior wall surface is needed to reduce the potential damages caused by driving rain [3]. Examples of listed buildings that have been energy retrofitted are available in the literature [4-6]. As for Sweden, an overview of four listed retrofitted buildings from the 1940s to 1960s in Gothenburg was presented by Johansson [7]. All the buildings had a brick façade and brick or aerated concrete walls. The retrofitting measures involved adding 30-50 mm glass wool on the exterior of the external walls, protected by either a layer of render or a ventilated façade board. The calculated Uvalue was reduced from $0.83-1.73 \mathrm{~W} / \mathrm{m}^{2} \mathrm{~K}$ to $0.13-0.5 \mathrm{~W} / \mathrm{m}^{2} \mathrm{~K}$ after the retrofitting depending on the existing construction and which measure that was used. Capener et al. [8] also studied 
Preprint version, Energy and Buildings, Available online 21 January 2014

http://dx.doi.org/10.1016/j.enbuild.2014.01.019

a brick building in Gothenburg which was retrofitted with an external thermal insulation composite (ETIC) system involving $50 \mathrm{~mm}$ glass wool and two layers of external render. Measurements showed a 27\% reduction in energy use and reduced moisture content in the wall. Another approach was proposed by Rasmussen [9] where $95 \mathrm{~mm}$ glass wool was added on the interior of a listed brick façade and $195 \mathrm{~mm}$ glass wool covered by render was added on the exterior of the remaining façades of a building from year 1900 in Copenhagen, Denmark. Often the thickness of the insulation layer is limited by the listing of the building since, in many cases, it is not allowed to change the exterior appearance of the façade, e.g. the depth of window placements and wall to roof connection. With high performance thermal insulation materials such as vacuum insulation panels (VIP), the required thickness of the insulation layer is reduced for the same thermal resistance. Alternatively a higher thermal resistance can be obtained with the same added thickness. Therefore it could be more appropriate to use VIP than conventional insulation materials when retrofitting the building envelope of listed buildings.

Examples of a number of different constructions where VIP has been used in retrofitted building envelopes have been reported in the literature. During 2002-2005 the international efforts in VIP research were assembled in the IEA/ECBCS Annex 39 High Performance Thermal Insulation (HiPTI). The project included monitoring and evaluation of 20 buildings with VIP in floors, roofs, walls, dormer windows and other constructions [10]. The number of case studies where VIP was used in façades is limited, but there exists studies of VIP used both on the interior [11, 12] and exterior [13-15] of existing external walls. Some practical issues when retrofitting with VIP on the exterior were discussed by Zwerger and Klein [15] who investigated the use of VIP in an ETIC system such as the one presented in Figure 1. 

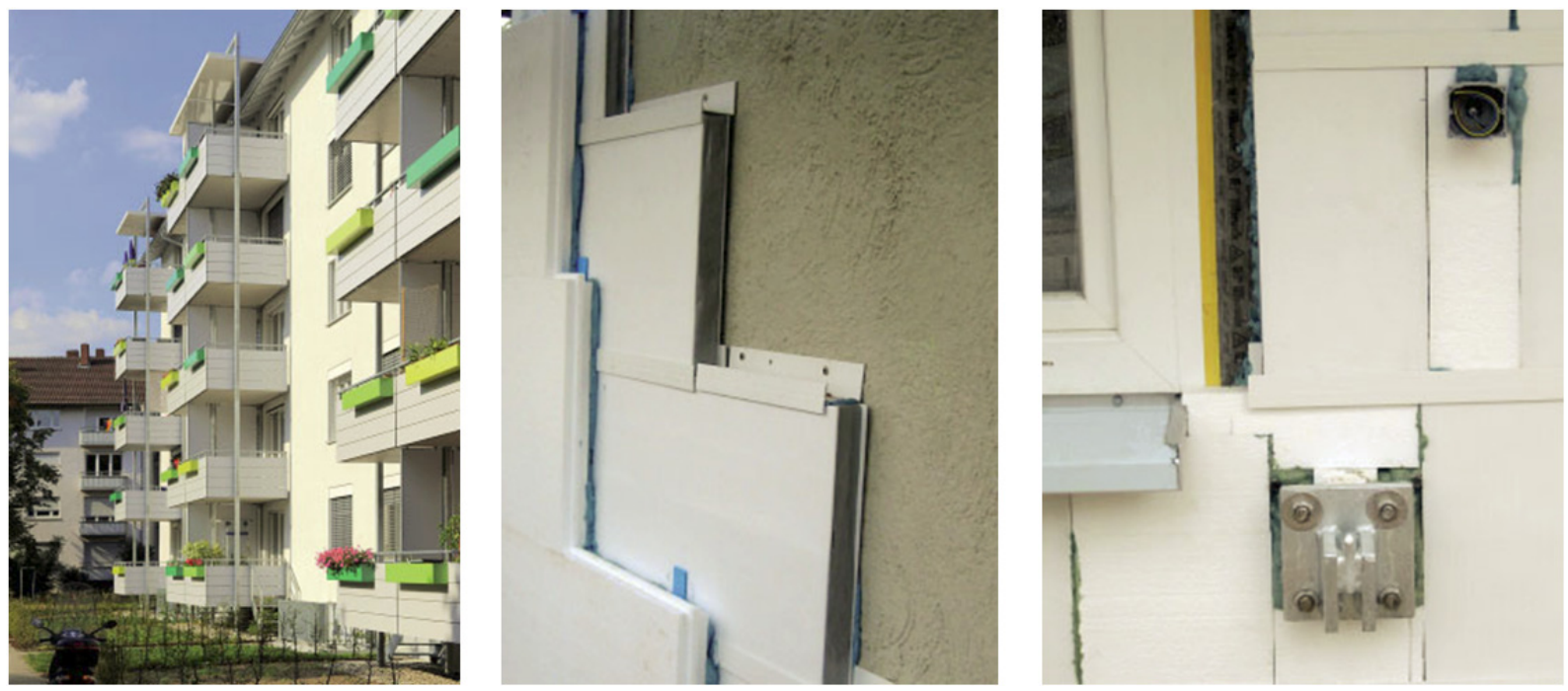

Figure 1. VIP used in the retrofitting of a multi-family building in Karlsruhe, Germany. The $40 \mathrm{~mm}$ thick VIP was attached to the façade in a rail system and covered on the exterior by $50 \mathrm{~mm}$ EPS. The aim of the design was to maximize the surface covered by VIP (Photo: Schöck Balkonsysteme GmbH, Brillux GmbH \& Co. KG).

The aim of this study is to explore how VIP can be used when retrofitting listed buildings to improve the thermal transmittance and moisture performance of the walls and the thermal comfort for the occupants. The hygrothermal consequences of adding VIP to an existing construction is not well investigated. Most studies focuses on the thermal performance [16] and energy use [17]. However, there are exceptions where also the moisture performance was evaluated in laboratory investigations [18, 19]. Dreyer and Korjenic [12] discussed the risk of damages to the existing construction due to the changed hygrothermal conditions in the wall. In this study a brick and homogenous timber wall lacking thermal insulation was insulated on the exterior with VIP. The changed moisture performance of the existing structure and the influence by thermal bridges are analyzed and compared to an uninsulated reference wall. A pre-study where the retrofit design was investigated using a hygrothermal simulation tool was presented in [20]. The simulated temperature and relative humidity can now be compared to the 2.5 years measurements in the retrofitted wall. The simulations are refined using the measured indoor and outdoor climate together with more accurate material data and longitudinal air flow paths in the wall to explain the deviations between the simulated and measured hygrothermal performance. 
Preprint version, Energy and Buildings, Available online 21 January 2014

http://dx.doi.org/10.1016/j.enbuild.2014.01.019

\section{Vacuum insulation panels}

Vacuum insulation panels (VIP) are commonly used in refrigerators, freezers and cold shipping boxes where the space for insulation is limited. The component was introduced in the mid-1980s following the search for materials that could replace insulation materials which contained chlorofluorocarbons (CFCs), harmful to the ozone layer. The potential of using VIP in buildings was discussed by Simmler et al. [21] who argued that the energy use for heating of the old buildings in Europe could be reduced by a factor of three. This reduction leads to a decrease in the $\mathrm{CO}_{2}$ emissions in the European Union by $8 \%$, fulfilling the agreement by the European Union in the Kyoto Protocol. The higher thermal resistance of the VIP also increases the area which can be used for living by $9 \%$ compared to using conventional insulation materials in a single-family house [21]. However, VIP cannot be installed in buildings without considering the limitations of the component. The production of VIP results in rigid panels of defined shape and sizes which cannot be adapted on the construction site. The panels have to be treated carefully in all stages of the handling since damages eventually leads to loss of vacuum and a fivefold increase in the thermal conductivity. Over time, air and moisture leak into the VIP also leading to an increased thermal conductivity. The technical life time of a refrigerator is around 10-20 years, which is much shorter than what can be expected from a building. Buildings should typically last for 80-100 years without too much maintenance of the building envelope while VIP available today typically has a service life of around 25-40 years [22].

\subsection{Core material and laminate}

VIP is a composite which can be divided in two parts; the core material and the laminate, as shown in Figure 2. The core material is a fine powder or fiber which is evacuated to pressures of 0.2-3 mbar and therefore should be able to resist the atmospheric pressure on the laminate, i.e. $0.1 \mathrm{MPa}$ or $10 \mathrm{metric}$ tons $/ \mathrm{m}^{2}$, without changing dimensions over time. The most common core material for VIP used in buildings in Europe is fumed silica while also glass wool and open cell polyurethane are common for other applications areas where the service life is shorter. Fumed silica is a material used in semiconductor industry and in the production of photovoltaic cells. It is produced by pyrolysis of silicon tetrachloride, $\mathrm{SiCl}_{4}$, which is vaporized and reacts with oxygen to form silicon dioxide, $\mathrm{SiO}_{2}$ [23]. To reduce the heat transfer by radiation inside the pores of the fumed silica silicon carbide, $\mathrm{SiC}$, is added to the 
Preprint version, Energy and Buildings, Available online 21 January 2014

http://dx.doi.org/10.1016/j.enbuild.2014.01.019

silica. A fiber material is used to increase the stability of the mixture before it is wrapped in the laminate.

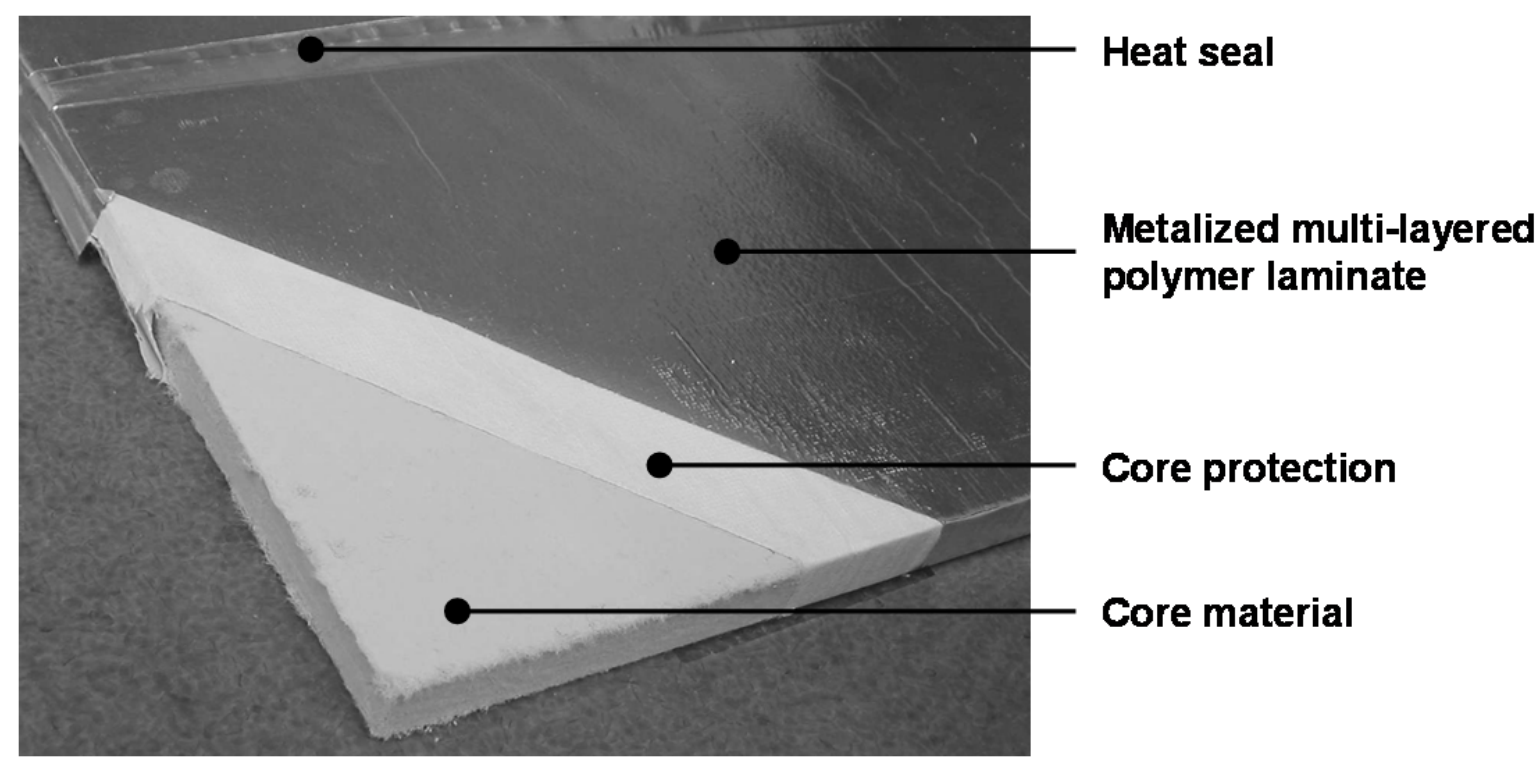

Figure 2. VIP is a composite with a fine powder core or fiber wrapped in a heat sealed metalized multi-layered polymer laminate (Photo: va-Q-tec AG).

Typically metalized multi-layered polymer laminates with thin aluminum layers $(30-100 \mathrm{~nm})$ are used to enclose the core material. On the long run the laminate is not perfectly gas tight which makes it possible for gas molecules to slowly diffuse through the laminate leading to an irreversible pressure increase that increases the thermal conductivity of the VIP. The pressure increase by the gas diffusion is in the order of 1-1.4 mbar/year in a constant climate of $23^{\circ} \mathrm{C}$ and 50\% relative humidity [22]. Also moisture diffusion through the laminate will lead to an increased thermal conductivity. Investigations of VIP stored in different climates in the laboratory has shown that after 25 years the thermal conductivity of a fumed silica VIP is around $8 \mathrm{~mW} /(\mathrm{m} \cdot \mathrm{K})$ [21]. If the laminate is damaged, the thermal conductivity increases to $20 \mathrm{~mW} /(\mathrm{m} \cdot \mathrm{K})$ which is still lower than e.g. glass wool which has a thermal conductivity around $40 \mathrm{~mW} /(\mathrm{m} \cdot \mathrm{K})$.

\subsection{Thermal conductivity of VIP}

The heat transfer through the core of the VIP is described by the center-of-panel thermal conductivity, $\lambda_{\text {cop }}(\mathrm{mW} /(\mathrm{m} \cdot \mathrm{K}))$, which can be divided in three parts:

$$
\lambda_{\text {cop }}=\lambda_{s}+\lambda_{g}+\lambda_{r} \mathrm{~mW} /(\mathrm{m} \cdot \mathrm{K})
$$


Preprint version, Energy and Buildings, Available online 21 January 2014

http://dx.doi.org/10.1016/j.enbuild.2014.01.019

where $\lambda_{s}$ is the thermal conductivity through the solid, $\lambda_{g}$ is the thermal conductivity through the gas and $\lambda_{r}$ is the radiative thermal conductivity within the pores. The pores of fumed silica are in the order of $100 \mathrm{~nm}$ which limits the thermal conductivity through the gas already at atmospheric pressure. The Knudsen number describes the decreasing thermal conductivity caused by the very small distance between the pore walls which limits the heat transfer between the gas molecules [24]. Inside the pores, the temperature difference is normally too low to induce gas convection. On material scale, however, there is gas convection through the open pore structure which cannot be neglected. In VIP, the gas convection is reduced firstly by the small pore size and additionally by removing the gas from the porous core material.

The metalized multi-layered polymer laminate which the core material is wrapped in, contributes to increasing the effective thermal conductivity of the VIP. The influence by the laminate can be described as the linear thermal transmittance, $\Psi(\mathrm{mW} /(\mathrm{m} \cdot \mathrm{K}))$. This value can be calculated numerically [25], analytically [26] or measured in a guarded hot plate apparatus [27-29]. The effective thermal conductivity of the VIP is then calculated by

$$
\lambda_{e f f}=\lambda_{c o p}+\Psi \cdot d \cdot P / A \mathrm{~mW} /(\mathrm{m} \cdot \mathrm{K})
$$

where $d(\mathrm{~m})$ is the thickness of the core, $P(\mathrm{~m})$ the circumference of the VIP and $A\left(\mathrm{~m}^{2}\right)$ the area of the VIP. The linear thermal transmittance is dependent on the center-of-panel thermal conductivity, the thermal conductivity of the laminate, the thickness of the panel and the thermal properties of the surrounding materials [10]. Schwab et al. [25] calculated the linear thermal transmittance for different boundary conditions with the surface heat transfer coefficient of $8 \mathrm{~W} / \mathrm{m}^{2} \mathrm{~K}$ on the interior and $25 \mathrm{~W} / \mathrm{m}^{2} \mathrm{~K}$ on the exterior surface. The linear thermal transmittance was $2 \mathrm{~mW} /(\mathrm{m} \cdot \mathrm{K})$ for a $20 \mathrm{~mm}$ thick VIP with no air gap along the perimeters of the panels and $12 \mathrm{~mW} /(\mathrm{m} \cdot \mathrm{K})$ for a $5 \mathrm{~mm}$ air gap [25]. In practical applications the width of the air gap between the panels is around 3-4 mm [29]. Measurements in guarded hot plate apparatus have shown that the linear thermal transmittance ranged between 9 and $15 \mathrm{~mW} /(\mathrm{m} \cdot \mathrm{K})$ for a $20 \mathrm{~mm}$ thick VIP which is in agreement with the calculations by Schwab, Stark, Wachtel, Ebert and Fricke [25].

\subsection{Long-term durability prediction of VIP}

In Europe, the declared thermal conductivity of insulation materials is given as the average performance over 25 years [30]. All materials change with time, dependent on the surrounding conditions such as temperature shifts, exposure to moisture and ultraviolet radiation. As discussed earlier, air and moisture slowly diffuse through the VIP laminate increasing the 
Preprint version, Energy and Buildings, Available online 21 January 2014

http://dx.doi.org/10.1016/j.enbuild.2014.01.019

internal pressure leading to a higher thermal conductivity. The lack of long-term experience from using VIP urges for accelerated ageing experiments to determine the long-term durability. Simmler and Brunner [22] investigated VIP in both constant and dynamic climate conditions. They found that the pressure and moisture increase in the VIP was in accordance with the Arrhenius equation. This means that the pressure and moisture diffusion doubles for each $10^{\circ} \mathrm{C}$ temperature increase. Based on this finding, an ageing model was developed which take into account the gas and moisture diffusion into the VIP. The ageing model was validated by Brunner and Simmler [31] who compared it to 2 years pressure and weight increase measurements performed on VIP installed in a flat roof of an occupied building in Switzerland. The model predicted the pressure increase with only $1.1 \%$ to $2.4 \%$ deviation while the increasing moisture content was overestimated with $67 \%$ to $80 \%$. According to Brunner [32] the calculated pressure increase by Brunner and Simmler [31] was actually overestimated because the laminate in the roof was of a different quality than the one used as input for the ageing model. In 2013, the same flat roof was reopened [33] and the installed VIP where transported to a lab for measurements of the thermal conductivity. The measurements showed that the thermal conductivity indeed had increased more than could be expected based on the ageing model. After 8.8 years the thermal conductivity had increased to $6.6 \mathrm{~mW} /(\mathrm{m} \cdot \mathrm{K})$ respective $7 \mathrm{~mW} /(\mathrm{m} \cdot \mathrm{K})$ while $5.6 \mathrm{~mW} /(\mathrm{m} \cdot \mathrm{K})$ was expected. To improve the accuracy of the model, Brunner and Ghazi Wakili [33] suggested a third ageing mechanism. They proposed that long-term moisture induced changes of the interfacial contact areas between the fumed silica particles could increase the thermal conductivity through the solid. Work still remains to improve the model to take the moisture induced changes of the fumed silica into account. Using the model dveeloped by Simmler and Brunner [22], the 25 year thermal conductivity of VIP in a moist environment is $8 \mathrm{~mW} /(\mathrm{m} \cdot \mathrm{K})$ while it is $7 \mathrm{~mW} /(\mathrm{m} \cdot \mathrm{K})$ for a dry application such as an exterior wall [31]. However, these predictions may now be considered too optimistic, especially for the moist condition which needs more investigations $[32]$.

\subsection{VIP in building envelopes}

Since VIP can only be ordered in predefined shapes and sizes and cannot be adapted on the construction site, the retrofit design of the building envelope has to be very detailed. The arrangement of each VIP has to be determined before the material can be ordered from the producer. One difficulty when retrofitting old buildings is the existence of cracks and imperfections. It is a challenge for the designers and construction workers to install VIP in an 
Preprint version, Energy and Buildings, Available online 21 January 2014

http://dx.doi.org/10.1016/j.enbuild.2014.01.019

existing construction and thorough investigations of the old materials in the existing construction is needed. At the positions where VIP is unsuitable, such as at balcony attachments and window-to-wall attachments, other insulation materials that can be adapted on the construction site have to be used. In this study glass wool boards have been used at such locations.

Another issue when using VIP is the risk of puncturing of the laminate, leading to loss of vacuum and an increased thermal conductivity. Heinemann and Kastner [16] used infrared thermography to investigate 19 objects insulated with in total $3224 \mathrm{~m}^{2}$ VIP, a few years after the construction finished. Three objects stood out in the investigation with more than $15 \%$ of the VIP damaged. In one of these objects it was assumed that errors were made in the design by installing unprotected panels close to an uneven plaster surface. In another project photos from the construction site showed that the VIP had been stored and handled improperly by the construction workers. In the remaining 16 objects with $1999 \mathrm{~m}^{2}$ VIP, the total percentage of damaged VIP was $4.9 \%$. In some of the very first objects, an alkaline glue was used which is not recommended today since it will deteriorate the thin aluminum layers in the laminate around the VIP leading to reduced service life. The conclusion of the study was that the percentage of damaged panels installed in a construction is low, as long as the recommendations by the producers are followed [16]. It should be noted that the study was based on infrared thermography which is a technique only possible to use when the VIP is not covered by a highly conductive material or a ventilated air space. This is an important limitation when evaluating the thermal performance and durability of the VIP in a finished wall.

\section{Field study building in Gothenburg, Sweden}

The building chosen for the study is a landshövdingehus "County governor's house" built in 1930 in Gothenburg, Sweden, see Figure 3. This is a typical historical building for the city of Gothenburg, located on the Swedish west coast. Most of these buildings were constructed during 1876-1936 when fire regulations limited the height of wood buildings to two floors. After the county administrative board approved buildings with two wood floors on top of a brick or stone masonry ground floor, the building type became very popular. Today there are over 1400 similar buildings in the Gothenburg region although many were demolished in the 1960-1970s. Today, the exterior aesthetics of the buildings are protected by Swedish legislation as a cultural environment of national interest. The buildings are inhabited with 
Preprint version, Energy and Buildings, Available online 21 January 2014

http://dx.doi.org/10.1016/j.enbuild.2014.01.019

many complaints on draught and insufficient thermal comfort from the occupants. Therefore the buildings are in great need of retrofitting measures.
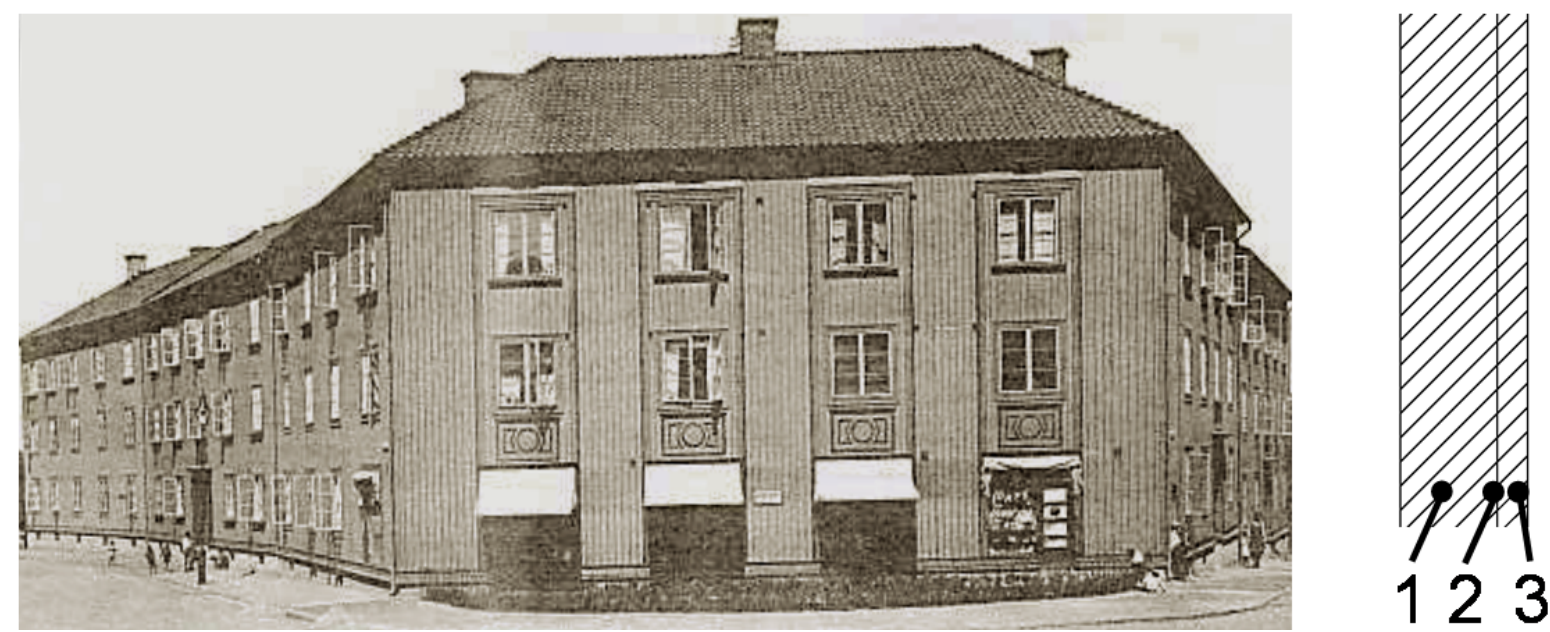

Figure 3. Landshövdingehus “County governor's house” in Gothenburg, Sweden. A façade in 1930 (left) and the construction of the original wood wall (right). 1) Structural wood or brick, 2) Tar paper, 3) Wooden cover boarding. (Photo from Sören Nilsson's collection of postcards; Pär Johansson).

\subsection{Original construction from 1930}

In the time when the building was constructed, thermal insulation was normally not used in the walls. This building was no exception with brick walls of 1.5 stone thickness, approximately $340 \mathrm{~mm}$, in the ground floor. In the two upper wooden floors, the walls were made of $80 \mathrm{~mm}$ wooden planks in three layers. Flax fibers were used between the boards to decrease the air permeability of the wall. On the exterior, a $22 \mathrm{~mm}$ thick vertical wooden cover board with rib flanges was installed on top of a wind and waterproof tar paper as shown in Figure 3. The interior side of the walls was originally covered with a thin finish of plaster on reed [34], which was later replaced by modern plaster boards.

Before the retrofitting, in June, 2010, the walls were investigated to determine their hygrothermal status. The moisture content in the wall was measured by a two-pin capacitive sensor. For that purpose holes in the wooden cover board were drilled to reach the underlying structure. The moisture quotient was approximately $9 \%$ close to the exterior surface of the wooden planks while it was around $8 \%$ a few $\mathrm{cm}$ into the construction. In the brick grout, wooden laths were found which had a moisture quotient of $12 \%$ at the surface and $9.5 \%$ further in. The critical moisture quotient for mold growth and dry rot fungi is around $20 \%$ on a wood surface which is about twice what was found in the wall at the time of the 
Preprint version, Energy and Buildings, Available online 21 January 2014

http://dx.doi.org/10.1016/j.enbuild.2014.01.019

measurements. Accordingly, no moisture damages or decay were detected in the wall.

Because of the complaints from the occupants on the insufficient thermal comfort, the temperature inside the building was around $24-25^{\circ} \mathrm{C}$ which is higher than normal. The high temperature in the building has probably contributed to dry out the materials in the wall.

The theoretical U-value of the original wall is estimated by calculations to $1.1 \mathrm{~W} /\left(\mathrm{m}^{2} \mathrm{~K}\right)$, both in the brick and wooden parts, which was supported by information from infrared thermography. The thermography investigation was performed during a cloudy day in March, 2010. At the time of the investigation, the temperature in the room air was $21.3-25^{\circ} \mathrm{C}$ and $4-$ $5.2^{\circ} \mathrm{C}$ outdoor with mostly cloudy sky while the interior surface temperature was $1.5-2.4^{\circ} \mathrm{C}$ lower than the room air temperature. An approximate $U$-value $\left(\mathrm{W} /\left(\mathrm{m}^{2} \cdot \mathrm{K}\right)\right)$ of the wall was calculated by the following equation:

$$
U=\frac{T_{i}-T_{s i}}{\left(T_{i}-T_{e}\right) \cdot R_{s i}}\left(\mathrm{~W} / \mathrm{m}^{2} / \mathrm{K}\right)
$$

where $T_{i}, T_{s i}$ and $T_{e}$ are the temperatures in the room, on the wall and outdoor. $R_{s i}$ is the surface resistance on the interior, normally $0.13 \mathrm{~m}^{2} \mathrm{~K} / \mathrm{W}$. The resulting $\mathrm{U}$-value of the original wall is then around $0.67-0.98 \mathrm{~W} /\left(\mathrm{m}^{2} \mathrm{~K}\right)$ which corresponds faily with the calculated U-value.

Prior to the retrofitting, the entire façade was scanned by a laser to find the exact dimensions of the wall and exact positions of the windows. It was found that the entire façade leans several $\mathrm{cm}$ between the diagonally opposite corners of the building. The scanning also showed that the total area of the façade was $133 \mathrm{~m}^{2}$, whereof the two timber floors were $89 \mathrm{~m}^{2}$ in total and the brick floor was $44 \mathrm{~m}^{2}$. There were 12 windows on the façade measuring around $2.3 \mathrm{~m}^{2}$ each, varying in size and position.

\subsection{Retrofit solution using VIP}

Depending on which U-value that is targeted for the wall after retrofitting, the thickness of the VIP can be varied. The appearance of the building cannot be changed, which limits the overall thickness of the wall and thereby the U-value of the wall. The wall thickness is limited by the connection between the wall and the roof, and it should remain as it was before. Also the connection between the wall and a fire wall which separates the building from the wall of the next building, see Figure 7, should be kept.

The resulting U-value for different VIP thicknesses is presented in Figure 4. A protection layer of $30 \mathrm{~mm}$ glass wool boards was proposed to be installed over the entire VIP surface. The influence by the protection layer on the U-value is also shown in Figure 4. Discussions in 
Preprint version, Energy and Buildings, Available online 21 January 2014

http://dx.doi.org/10.1016/j.enbuild.2014.01.019

the design team and with the building owner Familjebostäder i Göteborg AB resulted in an allowed additional thickness of $80 \mathrm{~mm}$ without risking the original features of the façade. This solution demanded that the old windows were moved $80 \mathrm{~mm}$ outwards, to be in line with the new façade. The thickness of the VIP was decided to be $20 \mathrm{~mm}$. With the $30 \mathrm{~mm}$ thick layer of glass wool on the exterior of the VIP, $30 \mathrm{~mm}$ remained. An air space, $28 \mathrm{~mm}$ thick, was added to the façade, see Figure 5, to allow for drying of possible moisture entering through the wooden cover board.

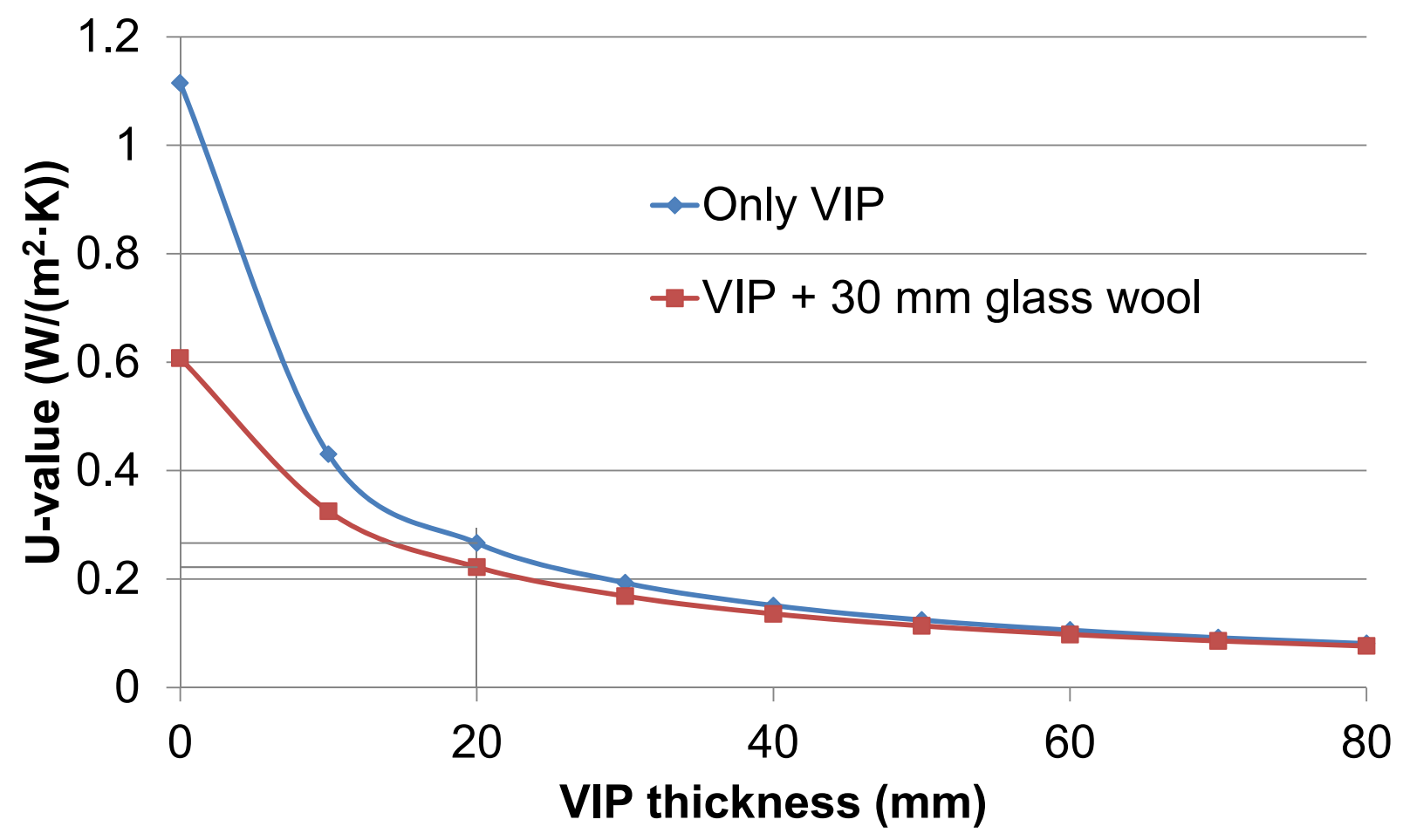

Figure 4. U-value as a function of the thickness of the VIP in the exterior brick wall, with and without $30 \mathrm{~mm}$ glass wool to protect the VIP. The chosen VIP thickness $20 \mathrm{~mm}$ is marked with the line. The thermal conductivity of the VIP was $0.007 \mathrm{~W} /(\mathrm{m} \cdot \mathrm{K})$ and $0.04 \mathrm{~W} /(\mathrm{m} \cdot \mathrm{K})$ for the glass wool.

One difficult detail of the design was the attachment of the wooden cover board on the façade. The chosen solution presented in Figure 5 shows distances of glass wool boards, $50 \mathrm{~mm}$ wide and $20 \mathrm{~mm}$ thick, between the VIP that allows for the wooden cover board to be attached without damaging the VIP. Another difficult detail was the insulation around the windows. The irregularities of the old wall made it impossible to use VIP here. Therefore glass wool was used to fill the space between the VIP and windows.

If the wall had been insulated with a continuous layer of $20 \mathrm{~mm}$ VIP, the theoretical U-value was $0.22 \mathrm{~W} /\left(\mathrm{m}^{2} \cdot \mathrm{K}\right)$, as shown in Figure 4 . However, the gaps filled with glass wool create 
Preprint version, Energy and Buildings, Available online 21 January 2014

http://dx.doi.org/10.1016/j.enbuild.2014.01.019

thermal bridges in the façade. Also the metalized multi-layered polymer laminate around the VIP contributes to a higher heat flow. With these thermal bridges taken into account, the effective U-value of the wall increased to $0.40 \mathrm{~W} /\left(\mathrm{m}^{2} \cdot \mathrm{K}\right)$ which is $82 \%$ higher than of an undisturbed wall. However, the calculated U-value of the wall after the retrofitting was reduced to $36 \%$ of the U-value before retrofitting, which is a substantial improvement.

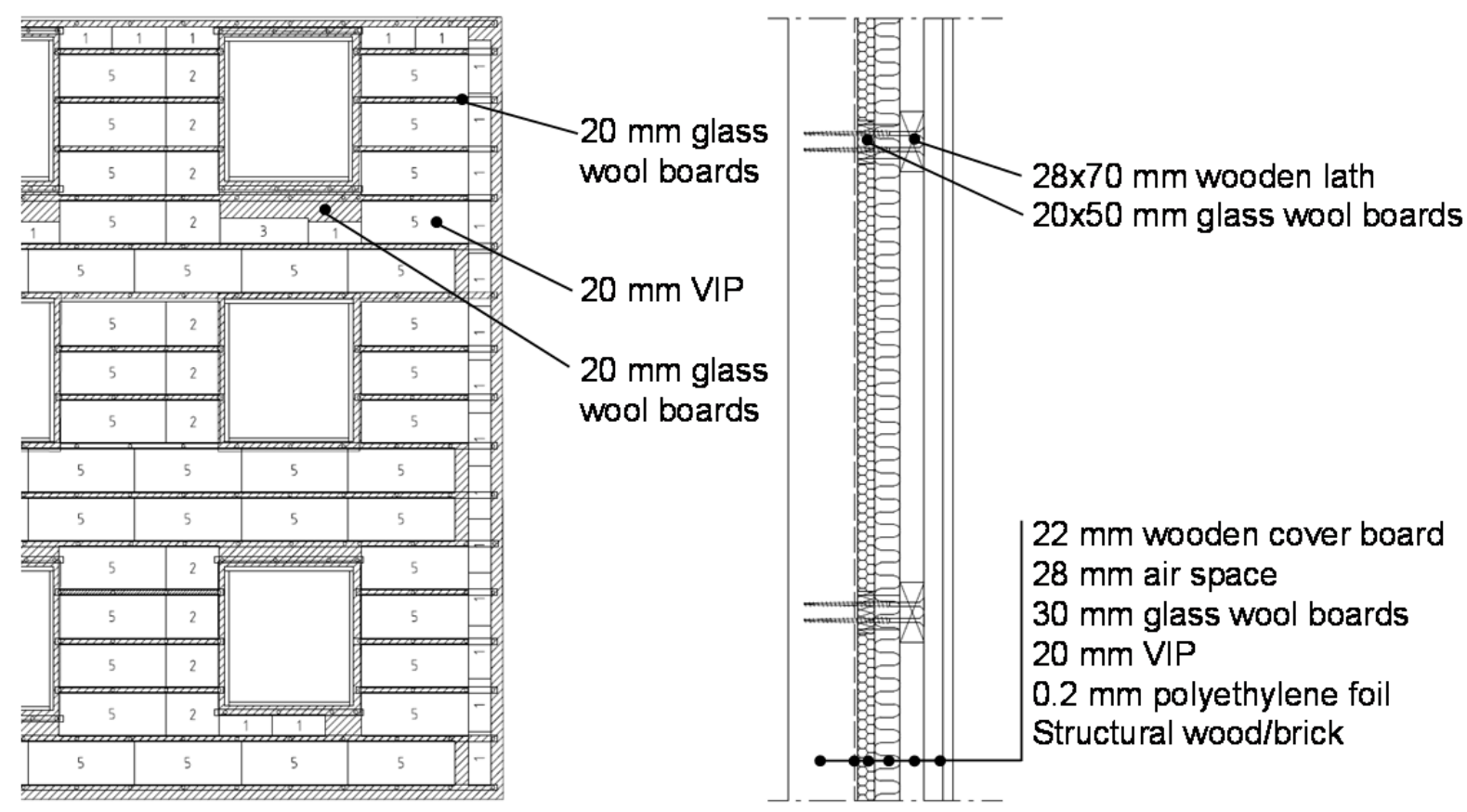

Figure 5. Wall layout after retrofitting with $20 \mathrm{~mm}$ VIP and $30 \mathrm{~mm}$ glass wool boards.

During the reconstruction phase of the façade it proved to be difficult to follow the new technical drawings of the façade. Although great concern had been given to the design of the wall to follow the original measurements, the laser scanning had been based on a point in the lower left corner of the façade which was removed when the old wooden cover board was torn down. This meant that the required number of VIP of specified sizes did not match the drawings. The problem was solved by rearranging the original layout and by ordering additional panels, $10 \%$ of each size. At the end only minor changes had to be done to the original design. Of the 180 panels installed in the wall three panels $(1.7 \%)$ had a loose laminate which meant they had been punctured or damaged before they reached the construction site or during construction. These VIP were exchanged to panels without visibly detectable damages.

\subsection{Calculated energy use reduction}

It was not possible to measure the energy use for heating and domestic hot water in the building since the heat was supplied to a larger block of buildings by district heating. The 
Preprint version, Energy and Buildings, Available online 21 January 2014

http://dx.doi.org/10.1016/j.enbuild.2014.01.019

measured energy use for a similar building from 1930 in Gothenburg was $129 \mathrm{kWh} / \mathrm{m}^{2}$

annually [35]. A County governor's house with an annual energy use of $126 \mathrm{kWh} / \mathrm{m}^{2}$ was studied by Molander and Olofsson [36] who investigated different ways to reduce the peak heating power demand of the building. The simulation model adapted to their study was used here to calculate the expected reduction in energy use after the retrofitting. The model was developed in Matlab and Simulink [37] and validated by Mata [38]. The energy use is calculated by an energy balance for the building where one thermal zone is modeled on hourly resolution. The thermal inertia of the building is represented by its effective internal heat capacity and the temperature of the indoor air and all the interior surfaces are assumed to be the same. The energy use for heating is defined as the heating power required to maintain a given indoor temperature using a heating system with finite power and response time [38]. Internal heat gains from people and appliances, solar radiation, air leakages and natural ventilation are included in the simulation model [36].

Based on the technical drawings it was estimated that $21 \%$ of the façade was covered by windows with a U-value of $3 \mathrm{~W} / \mathrm{m}^{2} \mathrm{~K}$ which were kept after the retrofitting. The U-value of the roof and floor were estimated to be $0.5 \mathrm{~W} / \mathrm{m}^{2} \mathrm{~K}$ and $0.9 \mathrm{~W} / \mathrm{m}^{2} \mathrm{~K}$ respectively. The U-value of the wall was calculated with regard to the thermal bridges created by the glass wool between the VIP and around windows, and the laminate around the VIP. The total average Uvalue was increased by $5 \%$ to include the additional thermal bridges between building elements. Figure 6 shows the reduction in the total energy use dependent on the percentage of undamaged VIP compared to the case before retrofitting. 


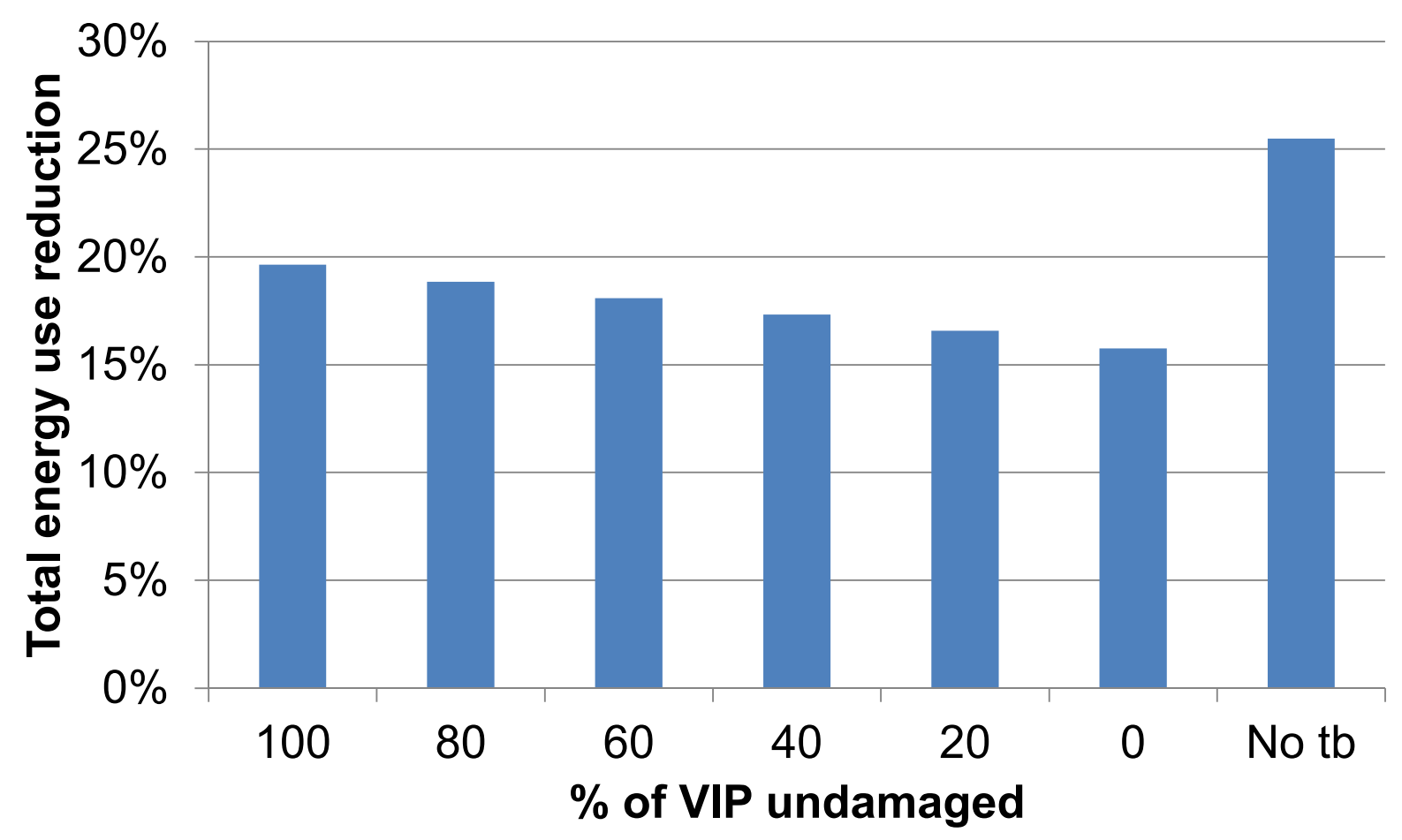

Figure 6. Reduction in total energy use for different scenarios of the percentage of undamaged VIP compared to the case without any thermal bridges (No tb) between the VIP.

The calculated energy use before retrofitting was $158.7 \mathrm{kWh} / \mathrm{m}^{2}$ for heating and domestic hot water. The total energy use was reduced with more than $25 \%$ for the case with an unbroken VIP layer and without any thermal bridges. With regard to the thermal bridges in the façade, the reduction became $20 \%$ with all the VIP undamaged which was further reduced to $16 \%$ if all the VIP were punctured. As a comparison, changing the windows to windows with a Uvalue of $1 \mathrm{~W} / \mathrm{m}^{2} \mathrm{~K}$ gave an energy use reduction of $15 \%$. The combination of changing windows and installing VIP gave an energy use reduction of $34 \%$.

\subsection{Temperature and relative humidity measurements}

The aim of the measurements is to investigate how the existing structure is influenced when installing additional thermal insulation on the exterior, and to identify locations where there is an increased risk of durability issues. A wall of roughly the same size next to the retrofitted wall was chosen as a reference case. Figure 7 shows the reference wall and the retrofitted wall with the approximate locations of the temperature and relative humidity sensors marked. As shown in Figure 7, and more detailed in Figure 8, four sensors were installed in the retrofitted brick and wood wall each. In the wood wall, one sensor was located behind the center-ofpanel, VIP-VIP connection, glass wool strip and window frame on the interior of the polyethylene foil. The intention was to have an identical layout in the brick wall, but the exact 
Preprint version, Energy and Buildings, Available online 21 January 2014

http://dx.doi.org/10.1016/j.enbuild.2014.01.019

location behind the VIP-VIP connection was missed and the sensor was located too low which meant two sensors monitored the glass wool strip. In the reference façade, two sensors were located behind the wooden cover board, as shown in Figure 7, one in the brick and wood wall respectively. Furthermore, one sensor was located in the kitchen of each of the four apartments closest to the monitored part of the wall to obtain the indoor conditions. The final sensor monitors the outdoor temperature and relative humidity at the building site. It was located in a perforated plastic box placed underneath the roof eave facing southwest, as shown in Figure 7. Solar radiation influences the measurements and therefore it was not the air temperature that was measured, but an effective (solar-air) temperature of the wall. The sensor was protected from rain and the whole box was ventilated through a number of holes drilled in its bottom.

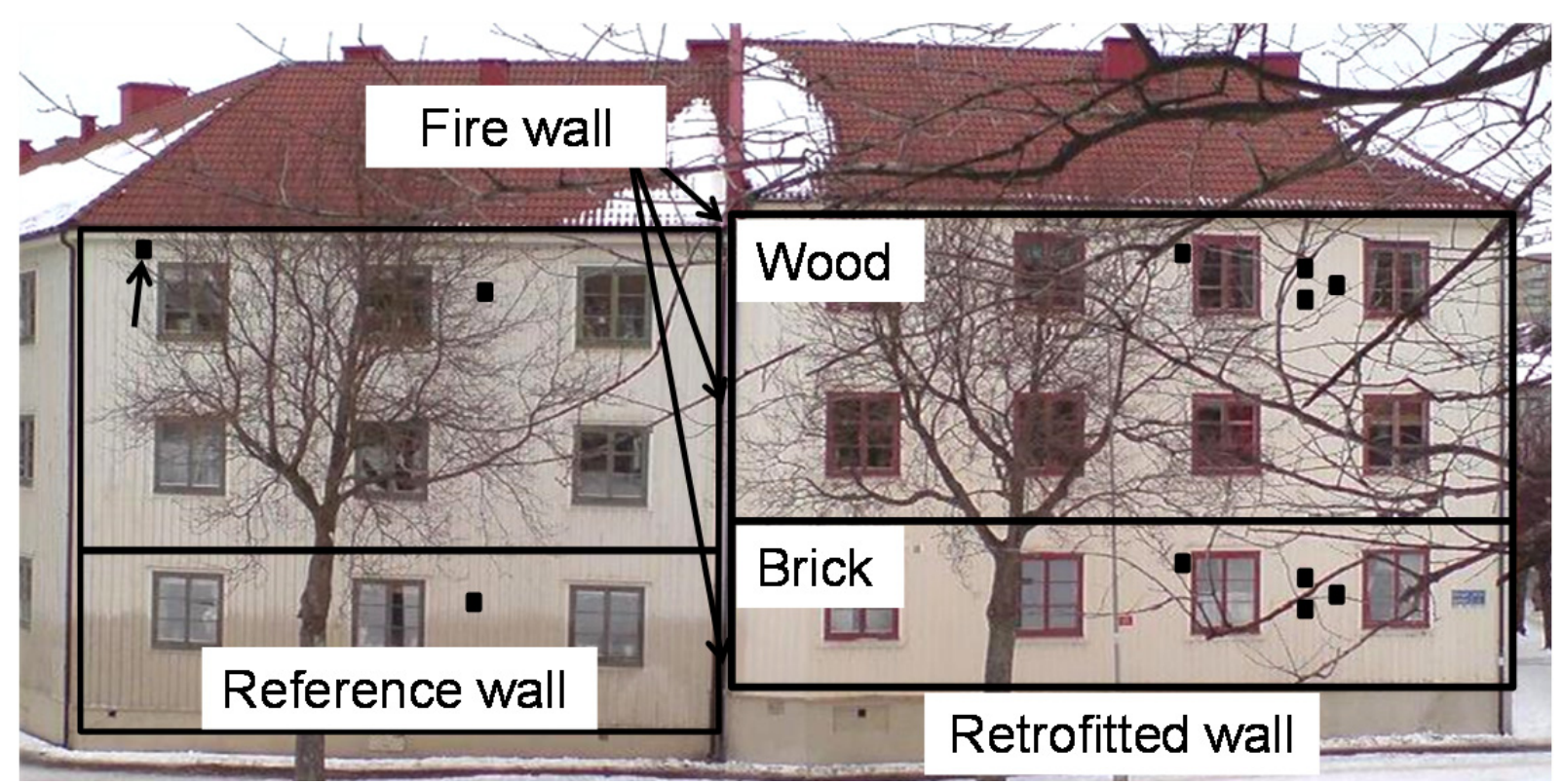

Figure 7. Reference and retrofitted wall with the approximate location of the sensors in the walls. Between the walls there is a thick brick fire wall separating the two buildings. The arrow in the upper left corner indicates the sensor monitoring the outdoor climate. 

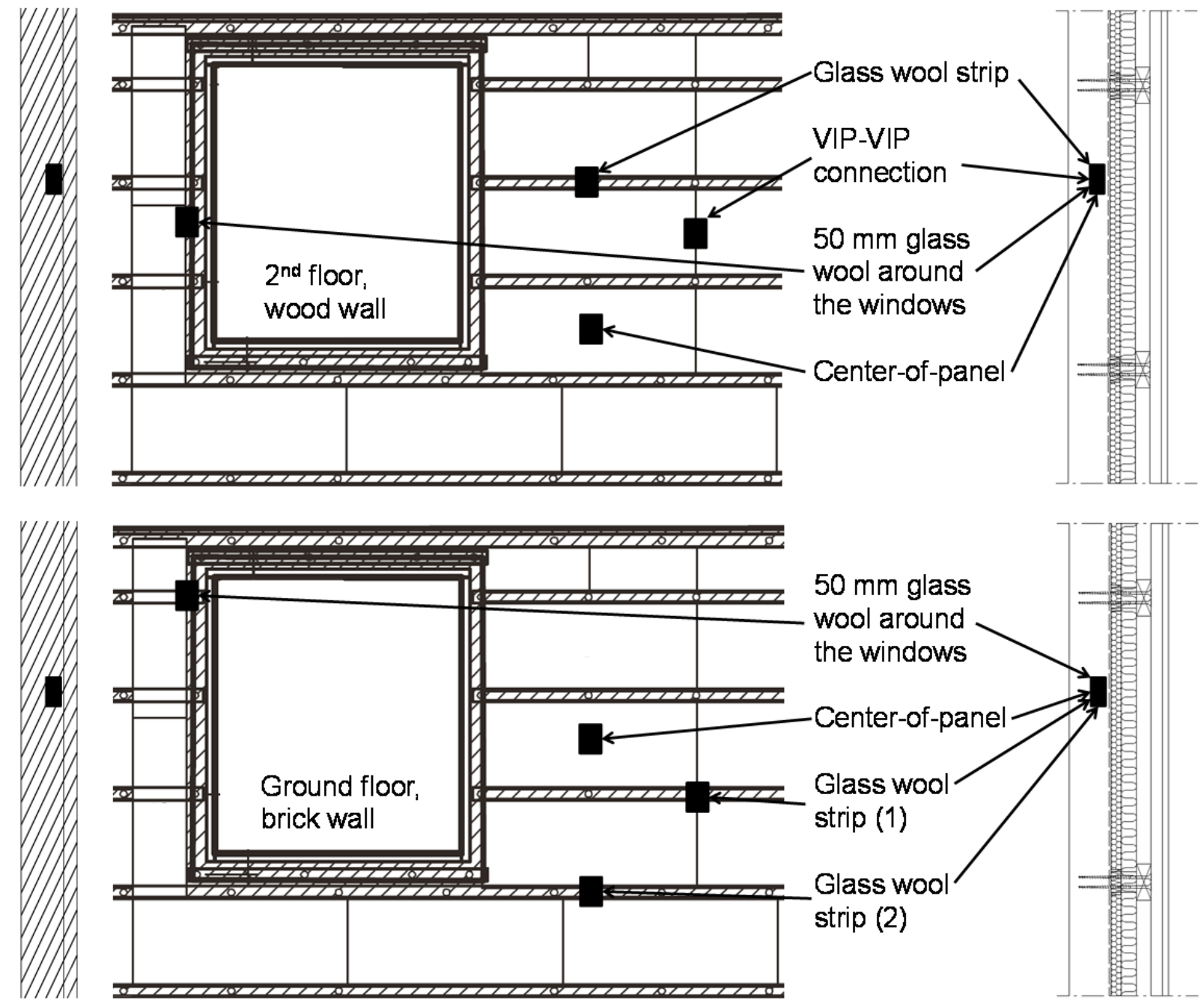

Figure 8. Location of sensors in the reference (left) and retrofitted wall (right). Upper: wood wall, lower: brick wall. The sensors in the reference wall were located behind the wooden cover boarding while all the sensors in the retrofitted wall were located in the existing wood on the interior of the polyethylene foil and VIP.

The sensors were driven by a battery with approximately 15 years lifetime. The signals from the sensors were collected through a wireless connection every hour by a gateway located on the attic. The sensors were 60x40x28 mm (length, width and height) and measured the temperature and relative humidity of the air in the void where the sensor was installed. The measurement accuracy of the sensors was $\pm 2.5 \%$ for relative humidity in the range of 10 to $90 \%$ and $\pm 0.5^{\circ} \mathrm{C}$ at $25^{\circ} \mathrm{C}$. The temperature could be measured between -40 to $85^{\circ} \mathrm{C}$ [39]. The sensors were tested and calibrated by SP Technical Research Institute of Sweden before they were installed in the wall. 
Preprint version, Energy and Buildings, Available online 21 January 2014

http://dx.doi.org/10.1016/j.enbuild.2014.01.019

\subsection{Measurement problems}

There were several problems with the measurement equipment in the beginning of the monitoring. The wall was finished in October 2010 but the problems were not solved until early January, 2011. According to the producer of the system, the distance between the sensors and data acquisition gateway could be up to $46 \mathrm{~m}$. However, signals from some of the sensors were blocked and the sensors were not detected by the gateway. It could be the thick brick fire wall, see Figure 7, or the aluminum layers in the laminate around the VIP which created disturbances for the signals. The problems were partly solved when an additional data acquisition gateway was installed in the basement of the building, though a large part of the data from October, 2010 to early January, 2011 were lost.

It was noticed that the amount of missing data increased during summer. This was especially a problem for the sensors furthest away from the gateway, i.e. in the lower part of the brick wall and in the reference apartment on the bottom floor. The sensors were operating at the limit of their wireless range which caused link failure and the loss of data. About $30 \%$ of the data was missing during June to July in 2012 and 17\% during the same period in 2011. In winter time, there was less missing data which indicated that the integrated circuits in the sensors worked better in the cold [40].

The sensor measuring the outdoor climate failed on 15 February, 2013 and was replaced on 27 March, 2013. During this period no data was available for the outdoor climate.

\section{Results from 2.5 years monitoring}

The sensors in the wall have been monitoring the temperature and relative humidity on the different locations since October, 2010. Despite the initial problems, there is almost 2.5 years of data available for the analysis. Before and after the retrofitting, the building was investigated with thermography and blower door. As mentioned above, a pre-study using a hygrothermal simulation tool was performed before the final retrofit solution was chosen [20]. The results from these simulations can now be compared with the measurements and the model calibrated using the measured data.

\subsection{Air tightness and thermography}

The air tightness of the wall was measured after the retrofitting finished, and compared to the case before retrofitting. Only measurements in single rooms were performed since it was only one of the façades that was equipped with VIP. The results before the retrofitting showed that 
Preprint version, Energy and Buildings, Available online 21 January 2014

http://dx.doi.org/10.1016/j.enbuild.2014.01.019

the airtightness at $50 \mathrm{~Pa}$ pressure gradient was $2.6 \mathrm{l} /\left(\mathrm{s} \cdot \mathrm{m}^{2}\right)^{1}(5.7 \mathrm{l} / \mathrm{h})$ for a room on the ground floor and $4.3 \mathrm{l} /\left(\mathrm{s} \cdot \mathrm{m}^{2}\right)(3.4 \mathrm{1} / \mathrm{h})$ for a room on the second floor. After the retrofitting the airtightness was $2.7 \mathrm{l} /\left(\mathrm{s} \cdot \mathrm{m}^{2}\right)(5.9 \mathrm{l} / \mathrm{h})$ for a room on the ground floor and $3.8 \mathrm{l} /\left(\mathrm{s} \cdot \mathrm{m}^{2}\right)(3.0 \mathrm{1} / \mathrm{h})$ for a room on the second floor. It is not possible to draw a certain conclusion on how the airtightness was influenced by the retrofitting. There were still large air leakages around the windows, at the connection between the interior and exterior wall and along the floor. These leakages could be connected to the surrounding rooms which were heated, or to the unheated basement, or to the outdoor environment.

Thermography was used to evaluate the increased thermal resistance of the wall after the retrofitting. The results of the thermography investigation before the retrofitting were presented in Section 3.1. The measured interior surface temperature was $1.5-2.4^{\circ} \mathrm{C}$ lower than the indoor air temperature which, by using Equation (3), gave a U-value of 0.67-0.98 $\mathrm{W} /\left(\mathrm{m}^{2} \mathrm{~K}\right)$. These results are compared to thermography performed a year later on a mostly cloudy day in March, 2011, after the wall was retrofitting. At the time of this second investigation, the temperature in the room air was $23.1-25.4^{\circ} \mathrm{C}$ and $4-7.2^{\circ} \mathrm{C}$ outdoor. The interior surface temperature was $0.3-0.8^{\circ} \mathrm{C}$ lower than the room air temperature which is a smaller difference than what was the case before the retrofitting. The resulting U-value using Equation (3) was $0.12-0.36 \mathrm{~W} /\left(\mathrm{m}^{2} \mathrm{~K}\right)$ for the retrofitted wall which indicates a substantial improvement of the U-value. However, thermography is a very coarse method for evaluation of the U-value and only gives a snapshot based on the conditions at the time of the investigation. This is indicated by the large spans of the measured temperatures and the calculated U-values. Despite the measurement uncertainties, it is clear that the U-value of the wall has been substantially improved after the retrofitting.

\subsection{Effective outdoor wall temperature and relative humidity}

The measurements were started in October 2010, but as discussed earlier some data are missing because of problems with the sensors. There were some hours with missing data also later during the measurement period. These short gaps were filled by linear interpolation. Figure 9 presents the daily averaged measured effective outdoor wall temperature and relative humidity from January, 2011 to February, 2013.

\footnotetext{
${ }^{1}$ Area of the exterior wall
} 


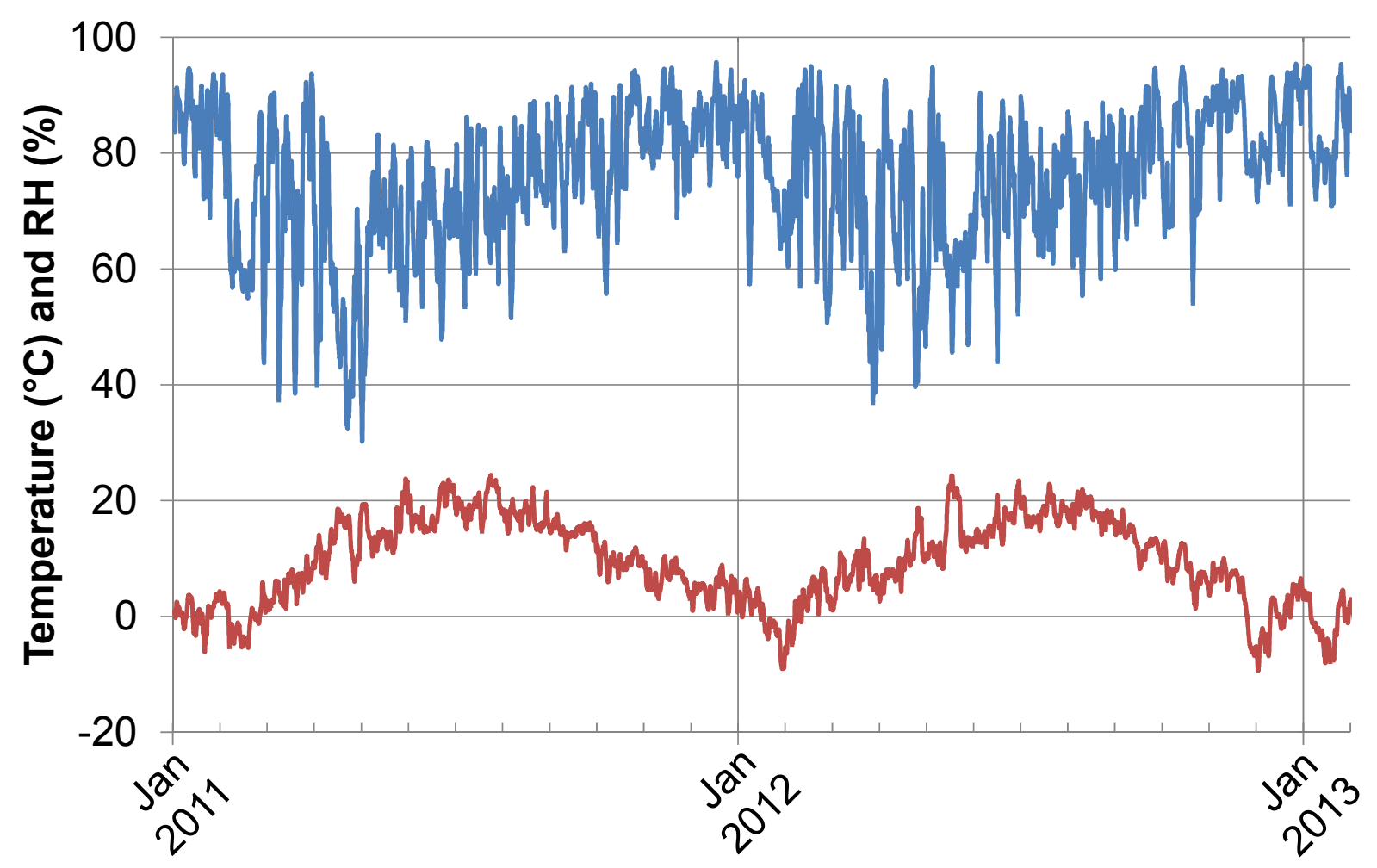

Figure 9. Daily averaged measured effective outdoor wall temperature and relative humidity during 2011, 2012 and January, 2013. The sensor is located in a perforated plastic box, exposed to solar radiation and some wind but protected from rain.

The annual average effective outdoor wall temperature was $10.3^{\circ} \mathrm{C}$ in 2011 and $9.3^{\circ} \mathrm{C}$ in 2012 , varying between $-10.4^{\circ} \mathrm{C}$ and $32.1^{\circ} \mathrm{C}$ in 2011 and $-12.7^{\circ} \mathrm{C}$ and $32.9^{\circ} \mathrm{C}$ in 2012 . The relative humidity was on average $74.4 \%$ in 2011 and $75.7 \%$ in 2012 , with the lowest relative humidity in 2011 of $16.9 \%$ and $16.4 \%$ in 2012 . The maximum relative humidity was $96.1 \%$ in 2011 and $96.5 \%$ in 2012. The two years were quite similar in regard of relative humidity while the annual average effective outdoor wall temperature was on average $1{ }^{\circ} \mathrm{C}$ higher in 2011 than in 2012. This deviation has to be taken into account in the analysis.

\subsection{Indoor temperature and relative humidity}

Four different apartments in the building were monitored where the temperature and relative humidity were measured in the kitchen of each apartment. The average indoor temperature, relative humidity and moisture excess during 2011 and 2012 are shown in Table 1. The moisture excess is defined by

$$
\Delta v=v_{i}-v_{e}\left(\mathrm{~g} / \mathrm{m}^{3}\right)
$$

where $v_{i}$ is the vapor content in the indoor air and $v_{e}$ is the vapor content in the outdoor air. 
Preprint version, Energy and Buildings, Available online 21 January 2014

http://dx.doi.org/10.1016/j.enbuild.2014.01.019

Table 1. Average indoor temperature, relative humidity and moisture excess in the four apartments during 2011 and 2012.

\begin{tabular}{lccccc}
\hline & Year & Ground floor & Ref ground floor & $2^{\text {nd }}$ floor & Ref $2^{\text {nd }}$ floor \\
\hline Temperature & 2011 & 25.5 & 23.9 & 24.8 & 23.2 \\
\cline { 2 - 6 }$\left({ }^{\circ} \mathrm{C}\right)$ & 2012 & 24.8 & 22.5 & 24.2 & 22.7 \\
\hline Relative humidity & 2011 & 43.7 & 40.2 & 38.2 & 48.1 \\
\cline { 2 - 6 }$(\%)$ & 2012 & 45.4 & 43.1 & 38.8 & 50.6 \\
\hline Moisture excess & 2011 & 2.9 & 1.2 & 1.3 & 2.6 \\
\cline { 2 - 6 }$\left(\mathrm{g} / \mathrm{m}^{3}\right)$ & 2012 & 3.2 & 1.5 & 1.4 & 3.1 \\
\hline
\end{tabular}

The average indoor temperature in the apartments was higher in 2011 than in 2012 which could be explained by the higher effective outdoor wall temperature in 2011 . The average difference between the indoor temperature and the effective outdoor wall temperature in the four apartments was $0.3^{\circ} \mathrm{C}$ higher in 2012 than in 2011 which is less than the sensor accuracy of $\pm 0.5^{\circ} \mathrm{C}$. The relative humidity was similar for the two years, but differs with 10 percent points between the apartment with the highest and lowest relative humidity. The moisture excess was varying with more than $100 \%$ between the apartments: one apartment, each in the reference building and the retrofitted building, was represented in the highest and lowest moisture excess range. In Figure 10, the moisture excess during 2011, 2012 and January, 2013 are presented as monthly averaged values. 


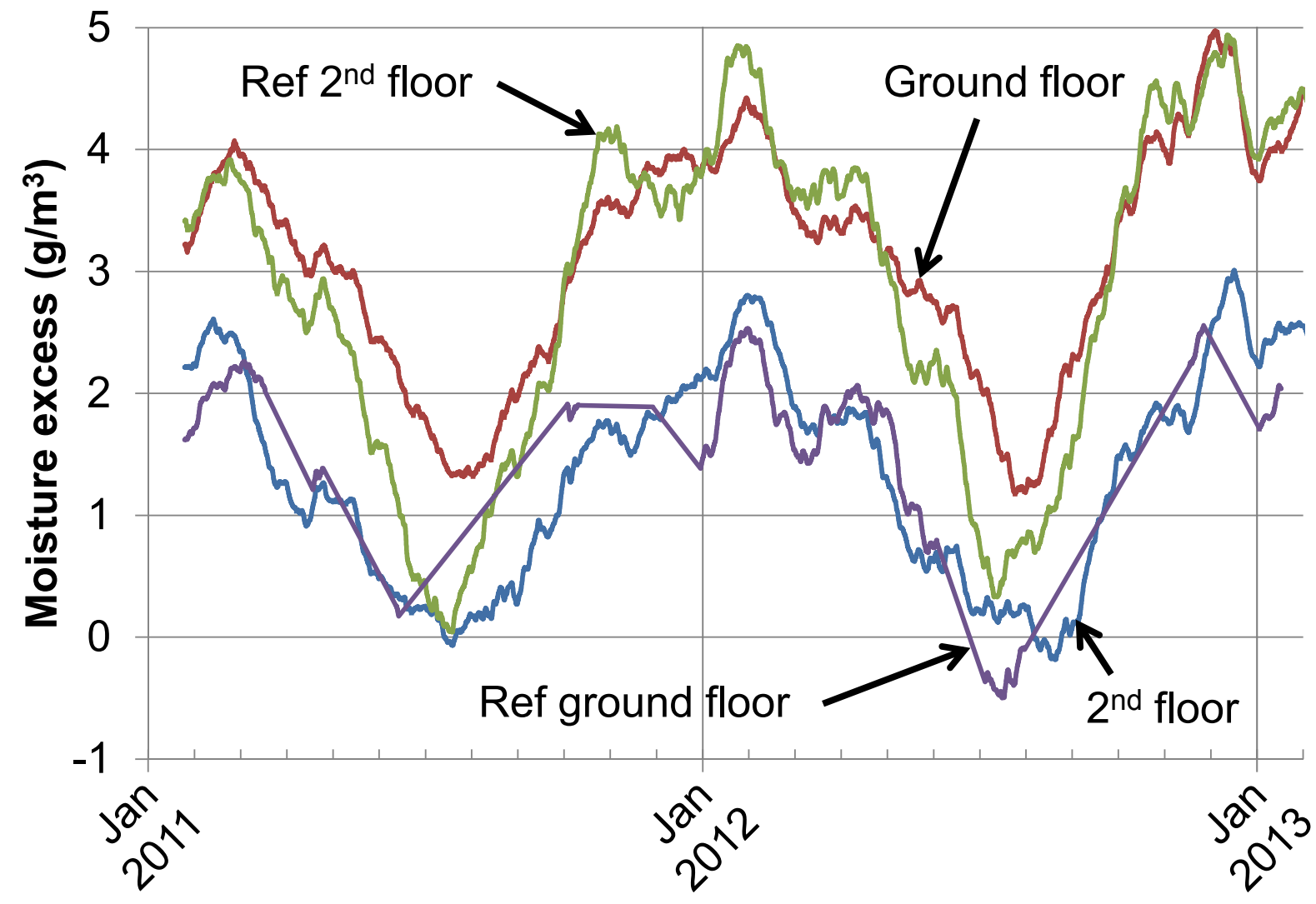

Figure 10. Monthly average moisture excess in the four apartments during 2011, 2012 and January, 2013. For the reference ground floor data for 131 hours (1.5\%) are missing during 2011 and 209 hours (2.4\%) during 2012 which explains the straight lines in the figure.

It is clear that the moisture excess varies during the year, with the highest values in the winter and lowest in the summer. This is probably caused by an increased airing by the occupants and less time spent indoors during summer time. The difference between the maximum and minimum moisture excess during the year was $4.9 \mathrm{~g} / \mathrm{m}^{3}$ in the reference apartment on the $2^{\text {nd }}$ floor during the year while it was $3.2 \mathrm{~g} / \mathrm{m}^{3}$ in the apartment on the $2^{\text {nd }}$ floor in the retrofitted building. Therefore, the retrofitting did not change the indoor climate more than what can be expected from the influence of the occupants' behavior.

\subsection{Temperature and relative humidity in the reference and retrofitted walls}

The relative humidity in the wall was already in a safe hygrothermal range before the retrofitting, i.e. around 70\% measured in June, 2010. This is also confirmed by measurements in the reference wall, as shown in Figure 11, where the temperature and relative humidity in the retrofitted wall (center-of-panel) are compared to the reference wall during 2011, 2012 and January, 2013. 

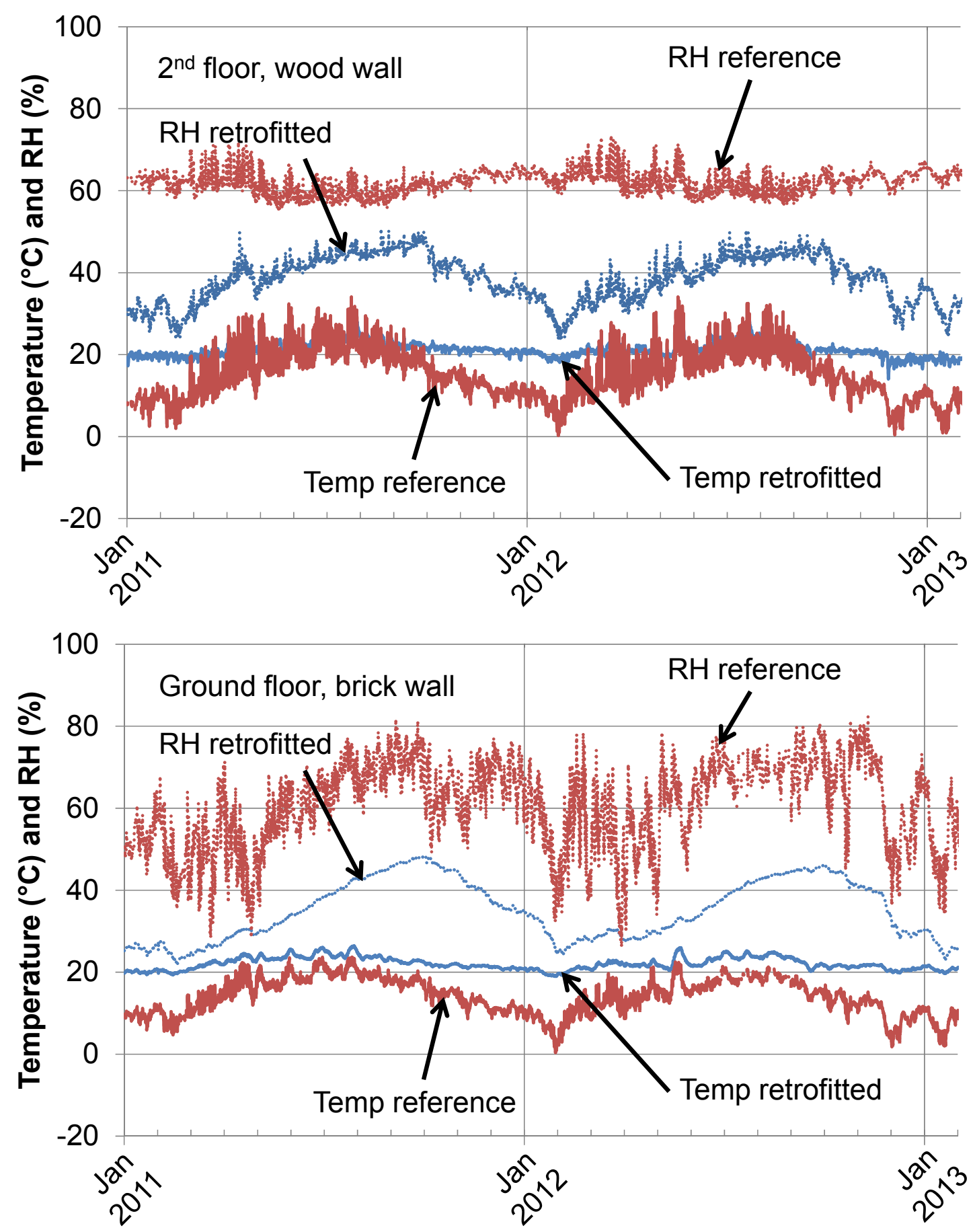

Figure 11. Temperature and relative humidity in the 2nd floor wall (top) and in the ground floor wall (bottom). The reference wall (center-of-panel) is compared to the retrofitted wall during 2011, 2012 and January, 2013.

The temperature in the reference and retrofitted walls differed substantially during 2012. In the ground floor reference wall the temperature varied between $0.4^{\circ} \mathrm{C}$ and $22.5^{\circ} \mathrm{C}$ with an average of $12.9^{\circ} \mathrm{C}$. In the retrofitted wall it varied between $19.0^{\circ} \mathrm{C}$ and $26.0^{\circ} \mathrm{C}$ with an average of $21.9^{\circ} \mathrm{C}$. As for the $2^{\text {nd }}$ floor, the temperature in the reference wall varied between $0.3^{\circ} \mathrm{C}$ and $34.1^{\circ} \mathrm{C}$ with an average of $14.8^{\circ} \mathrm{C}$, and it varied between $14.0^{\circ} \mathrm{C}$ and $28.3^{\circ} \mathrm{C}$ with 
Preprint version, Energy and Buildings, Available online 21 January 2014

http://dx.doi.org/10.1016/j.enbuild.2014.01.019

an average of $21.3^{\circ} \mathrm{C}$ in the retrofitted wall. The higher maximum temperature in the $2^{\text {nd }}$ floor walls suggests that they were exposed to more solar radiation than the ground floor walls were. The slower hourly variations in the brick wall could be explained by the thermal inertia which is higher in the brick wall compared to the wood wall.

Also the relative humidity is more stable during the year and substantially lower, on average, in the retrofitted wall. During 2012 the average relative humidity was $60.3 \%$ in the ground floor reference wall compared to an average of $35.4 \%$ in the retrofitted wall. The relative humidity varied between $26.2 \%$ and $82.4 \%$ in the ground floor reference wall compared to a variation between $24.4 \%$ and $46.1 \%$ in the retrofitted wall. In the reference wall on the $2^{\text {nd }}$ floor the relative humidity varied between $56.4 \%$ and $73.5 \%$ with an average of $62 \%$ compared to a variation between $23.7 \%$ and $50.5 \%$ with an average of $38.1 \%$ in the retrofitted wall.

The temperature and relative humidity can be used to calculate the vapor content in the wall. The yearly variations of the vapor content in 2012 in the retrofitted walls were much lower than in the reference wall, $6.0 \mathrm{~g} / \mathrm{m}^{3}$ compared to $12.6 \mathrm{~g} / \mathrm{m}^{3}$ in the ground floor wall and $10.0 \mathrm{~g} / \mathrm{m}^{3}$ compared to $23.9 \mathrm{~g} / \mathrm{m}^{3}$ in the $2^{\text {nd }}$ floor wall. In the reference ground floor wall the vapor content was on average $7.2 \mathrm{~g} / \mathrm{m}^{3}$ and in the retrofitted wall $6.9 \mathrm{~g} / \mathrm{m}^{3}$. In the reference wall on the $2^{\text {nd }}$ floor it was on average $8.3 \mathrm{~g} / \mathrm{m}^{3}$ compared to $7.2 \mathrm{~g} / \mathrm{m}^{3}$ in the retrofitted wall. In the reference wall, vapor can be transferred both to the interior and exterior side of the wall, while the exterior vapor transfer is blocked by the vapor barrier and VIP in the retrofitted wall. However, the lower vapor content in the retrofitted walls indicates a dryer wall after the retrofitting which means the drying capacity is sufficient. This is beneficial from a building physics perspective since the risk for mold growth and dry rot fungi is higher in constructions with high moisture contents.

As discussed earlier, the indoor moisture excess varied during the year and between the apartments. On the ground floor, the reference apartment had an moisture excess of $1.5 \mathrm{~g} / \mathrm{m}^{3}$ while it was $3.2 \mathrm{~g} / \mathrm{m}^{3}$ in the retrofitted apartment. The relation was the opposite in the $2^{\text {nd }}$ floor apartments where the reference apartment had the higher moisture excess of $3.1 \mathrm{~g} / \mathrm{m}^{3}$ compared to $1.4 \mathrm{~g} / \mathrm{m}^{3}$ in the retrofitted apartment. These differences could partly explain why the average vapor content was higher in the reference wall on the $2^{\text {nd }}$ floor than in the reference wall on the ground floor. However, they do not explain why the vapor content was higher in the retrofitted $2^{\text {nd }}$ floor wall than in the retrofitted ground floor wall, i.e. one would expect the opposite situation. 
Preprint version, Energy and Buildings, Available online 21 January 2014

http://dx.doi.org/10.1016/j.enbuild.2014.01.019

\subsection{Temperatures at the different locations of the retrofitted walls}

In an earlier publication [41], measurements in the retrofitted brick wall during the period January 5 to March 22, 2011 were analyzed and reported. The temperature was on average $10^{\circ} \mathrm{C}$ higher on the interior of the VIP compared to the corresponding location in the reference wall. There was also a small difference between the different locations on the interior of the VIP where the center-of-panel temperature was on average $1{ }^{\circ} \mathrm{C}$ higher than behind the glass wool laths. Now the same analysis can be performed using the 2.5 years measured data. Because of the missing data for some of the sensors, especially during the summer period, three winter months have been chosen for a deepened analysis of the differences in the hygrothermal performance of the reference and retrofitted wall. Table 2 presents the average temperatures during January, 2011, 2012 and 2013 in the retrofitted wall and reference wall respectively. The temperature differences between the center-of-panel and the other locations are also presented.

Table 2. Average temperatures and temperature differences between center-of-panel and the other locations, presented in Figure 8, in the retrofitted and reference wall in January, 2011, 2012 and 2013.

\begin{tabular}{llllllll}
\hline Floor & Location & \multicolumn{2}{c}{$2011\left({ }^{\circ} \mathrm{C}\right)$} & \multicolumn{2}{c}{$2012\left({ }^{\circ} \mathrm{C}\right)$} & \multicolumn{2}{c}{$2013\left({ }^{\circ} \mathrm{C}\right)$} \\
\hline \multirow{2}{*}{ 2nd floor } & VIP center & 19.7 & - & 19.8 & - & 18.8 & - \\
\cline { 2 - 7 } & VIP-VIP & 19.2 & 0.4 & 19.1 & 0.7 & 19.3 & -0.4 \\
\cline { 2 - 7 } & Glass wool & 18.8 & 0.9 & 18.7 & 1.2 & 18.0 & 0.9 \\
\cline { 2 - 7 } & Window & 17.4 & 2.2 & 15.8 & 4.0 & 16.2 & 2.6 \\
\cline { 2 - 7 } Ground floor & Reference & 8.5 & 11.2 & 8.0 & 11.8 & 7.2 & 11.6 \\
\cline { 2 - 7 } & GIP center & 20.2 & - & 20.0 & - & 20.7 & - \\
\cline { 2 - 7 } & Glass wool 1 & 19.0 & 1.2 & 18.8 & 1.3 & 19.5 & 1.2 \\
\cline { 2 - 7 } & Glass wool 2 & 19.4 & 0.8 & 19.3 & 0.8 & 19.8 & 0.9 \\
\cline { 2 - 7 } & Window & 15.6 & 4.5 & 15.7 & 4.3 & 15.0 & 5.7 \\
\cline { 2 - 7 } & Reference & 9.6 & 9.4 & 7.5 & 16.5 & 7.6 & 13.1 \\
\hline
\end{tabular}


Preprint version, Energy and Buildings, Available online 21 January 2014

http://dx.doi.org/10.1016/j.enbuild.2014.01.019

As discussed in Section 3.4 and shown in Figure 8, the measurement locations are not entirely the same for the two walls. This explains some of the differences between the ground floor and the $2^{\text {nd }}$ floor measurement results. As can be expected, the temperature was highest behind the center-of-panel in most cases. There was one exception where the temperature in January, 2013 behind the VIP-VIP on the $2^{\text {nd }}$ floor was higher than behind the center-of-panel location. The temperature was lower behind the glass wool laths, than at the VIP-VIP, where the thermal bridge was smaller. The lowest temperature in the retrofitted wall was found at the window frame where there was less insulation.

To evaluate the improved thermal performance of the wall, the temperature gradient of the retrofitted wall and the reference wall can be compared. Using the indoor temperature, the temperature behind the center-of-panel and effective outdoor wall temperature, the relative temperature difference can be calculated by

$$
\varepsilon=\frac{T_{\text {indoor }}-T_{\text {center-of }- \text { panel }}}{T_{\text {indoor }}-T_{\text {outdoor }}}(-)
$$

where the measured temperatures, $T\left({ }^{\circ} \mathrm{C}\right)$, are used. The relative temperature difference is 1 on the interior side of the wall and 0 on the exterior side. The relative temperature differences for the ground floor and $2^{\text {nd }}$ floor wall in the reference and retrofitted walls respectively in January, 2011, 2012 and 2013 are presented in Table 3.

Table 3. Relative temperature difference calculated using Equation (5) for January, 2011, 2012 and 2013.

\begin{tabular}{ccccc}
\hline & \multicolumn{2}{c}{ Ground floor } & \multicolumn{2}{c}{$2^{\text {nd }}$ floor } \\
\hline & Retrofitted & Reference & Retrofitted & Reference \\
\hline 2011 & 0.17 & 0.61 & 0.18 & 0.63 \\
\hline 2012 & 0.18 & 0.65 & 0.16 & 0.63 \\
\hline 2013 & 0.14 & 0.64 & 0.18 & 0.64 \\
\hline
\end{tabular}

It is clear that the thermal resistance of the wall has been substantially improved after the retrofitting. In the reference wall $83 \%$ of the temperature drop was caused by heat losses through the uninsulated brick and wooden parts respectively. After the retrofitting only $37 \%$ of the temperature drop was over that part of the wall. The expected relative temperature difference can be calculated by using the resistance on the interior and exterior side of the measurement location: 
Preprint version, Energy and Buildings, Available online 21 January 2014

http://dx.doi.org/10.1016/j.enbuild.2014.01.019

$$
\varepsilon=\frac{R_{\text {interior }}}{R_{\text {interior }}+R_{\text {exterior }}}(-)
$$

where $R_{\text {interior }}\left(\mathrm{m}^{2} \mathrm{~K} / \mathrm{W}\right)$ is the thermal resistance of the structural wall and $R_{\text {exterior }}\left(\mathrm{m}^{2} \mathrm{~K} / \mathrm{W}\right)$ is the thermal resistance of the materials on the exterior side of the sensor. The standard values for the thermal conductivities, $\lambda(\mathrm{W} /(\mathrm{m} \cdot \mathrm{K})$, the thickness of each material layer, $d(\mathrm{~mm})$, and the resulting thermal resistance, $R=d / \lambda\left(\mathrm{m}^{2} \mathrm{~K} / \mathrm{W}\right)$, are presented in Table 4.

Table 4. Standard values for the thermal conductivity, $\lambda(\mathrm{W} /(\mathrm{m} \cdot \mathrm{K}))$, of the materials in the wall and corresponding thermal resistances $R\left(\mathrm{~m}^{2} \cdot \mathrm{K} / \mathrm{W}\right)$ for the layers of thickness $d(\mathrm{~mm})$ and the heat transfer coefficient between the surface and air [42].

\begin{tabular}{lccc}
\hline & $d(\mathrm{~mm})$ & $\lambda(\mathrm{mW} /(\mathrm{m} \cdot \mathrm{K}))$ & $R\left(\mathrm{~m}^{2} \cdot \mathrm{K} / \mathrm{W}\right)$ \\
\hline Wood & 80 & 140 & 0.57 \\
\hline Cover board & 22 & 140 & 0.16 \\
\hline Brick & 340 & 700 & 0.49 \\
\hline VIP & 20 & 5 & 4.0 \\
\hline Glass wool & 30 & 40 & 0.75 \\
\hline Rsi & - & - & 0.13 \\
\hline Rse & - & - & 0.04 \\
\hline Rvented façade & - & - & 0.20 \\
\hline
\end{tabular}

As discussed earlier, the U-value of the retrofitted wall was higher than the calculated U-value of $0.22 \mathrm{~W} /\left(\mathrm{m}^{2} \cdot \mathrm{K}\right)$. Taking the thermal bridges into account, the calculated U-value increased to $0.4 \mathrm{~W} /\left(\mathrm{m}^{2} \cdot \mathrm{K}\right)$. These values were confirmed by the thermography investigation which gave a U-value in the range of $0.12-0.36 \mathrm{~W} /\left(\mathrm{m}^{2} \cdot \mathrm{K}\right)$. Based on the measured temperatures in the retrofitted wall and the standard values of the thermal conductivities in Table 4, the effective $\mathrm{U}$-value of the wall was $0.26 \mathrm{~W} /\left(\mathrm{m}^{2} \cdot \mathrm{K}\right)$.

Using the standard values for the thermal conductivity, the relative temperature difference at the sensor location was 0.77 in the reference wall and 0.12 in the retrofitted wall. The measurements gave an average relative temperature difference of 0.63 in the reference wall and 0.17 in the retrofitted wall. The lower measured relative temperature difference in the reference wall could be explained by a higher surface heat transfer resistance on the exterior of the wall. The sensor was located in a perforated plastic box placed underneath the roof 
Preprint version, Energy and Buildings, Available online 21 January 2014

http://dx.doi.org/10.1016/j.enbuild.2014.01.019

eave, mostly protected from wind, which leads to a higher surface heat transfer resistance than what was used in the first calculation. With an exterior surface heat transfer resistance of $0.22 \mathrm{~m}^{2} \cdot \mathrm{K} / \mathrm{W}$ instead of $0.04 \mathrm{~m}^{2} \cdot \mathrm{K} / \mathrm{W}$, the calculated relative temperature difference reached the measured relative temperature difference of 0.63 .

The thermal bridges created by the VIP laminate and glass wool strips could explain the higher measured relative temperature difference in the retrofitted wall compared to the calculation. These were not included in the calculation. In reality these thermal bridges increase the heat flow through the VIP layer. To reach the measured relative temperature difference of 0.17 , the effective thermal conductivity of the layer with VIP and glass wool strips needed to be $9 \mathrm{~mW} /(\mathrm{m} \cdot \mathrm{K})$. Using the exterior surface heat transfer resistance of $0.22 \mathrm{~W} /\left(\mathrm{m}^{2} \cdot \mathrm{K}\right)$, the effective thermal conductivity increased to $10 \mathrm{~mW} /(\mathrm{m} \cdot \mathrm{K})$. However, other factors could contribute to increasing the heat flow through the wall. One of these factors is airflow through the wall which was not considered above but is discussed more in detail in the next section.

\subsection{Measured temperature and relative humidity compared to simulations}

To evaluate the consequences of the changed hygrothermal conditions in the wall after the retrofitting, hygrothermal simulations were performed before the final retrofit solution was chosen. The results from this pre-study were presented in [20] and can now be compared to the 2.5 years measurements. The temperature and relative humidity was simulated using a two dimensional model of the wall, shown in Figure 12, in the hygrothermal simulation tool WUFI 2D [43]. The tool solves coupled heat and moisture transport equations by finite volumes where the temperature and relative humidity are the driving forces. The simulations can be calibrated using the measured boundary conditions to get a more accurate prediction of the long-term hygrothermal performance. In the earlier versions of the tool, which was used in the pre-study, air flows could not be modeled. Later it was possible to model air exchange of the interior or exterior air in the construction. This makes it possible to study the impact of air movement through the construction.

The simulations in the pre-study presented in [20] were performed using the material data and the reference climate file for Gothenburg from the WUFI 2D database [43]. Five consequent years were simulated with identical boundary conditions. The initial temperature and relative humidity in the materials was set to $15^{\circ} \mathrm{C}$ and $70 \%$. The climate for Gothenburg in the WUFI $2 \mathrm{D}$ database gives an outdoor temperature between $-12.2^{\circ} \mathrm{C}$ and $27.8^{\circ} \mathrm{C}$ with an average of 
Preprint version, Energy and Buildings, Available online 21 January 2014

http://dx.doi.org/10.1016/j.enbuild.2014.01.019

$8.8^{\circ} \mathrm{C}$. The outdoor relative humidity is on average $74.5 \%$ and ranges between $19 \%$ and $100 \%$. Two levels of the average indoor moisture excess were estimated based on the measurements in two apartments in June to August, 2010. The average moisture excess was $2.3 \mathrm{~g} / \mathrm{m}^{3}$ in one apartment and $3.9 \mathrm{~g} / \mathrm{m}^{3}$ in the second. These values were used as input data in the simulation to create two scenarios of the indoor moisture excess. The lower moisture excess scenario had an average indoor temperature of $21.1^{\circ} \mathrm{C}$ and $48.8 \%$ relative humidity while the higher moisture excess scenario had an average indoor temperature of $22.2^{\circ} \mathrm{C}$ and $53.3 \%$ relative humidity. The simulation results presented in [20] for the two levels of moisture excess are compared in Figure 12 to the measurements in the wall during the period 7 January, 2011 to 3 April, 2013.

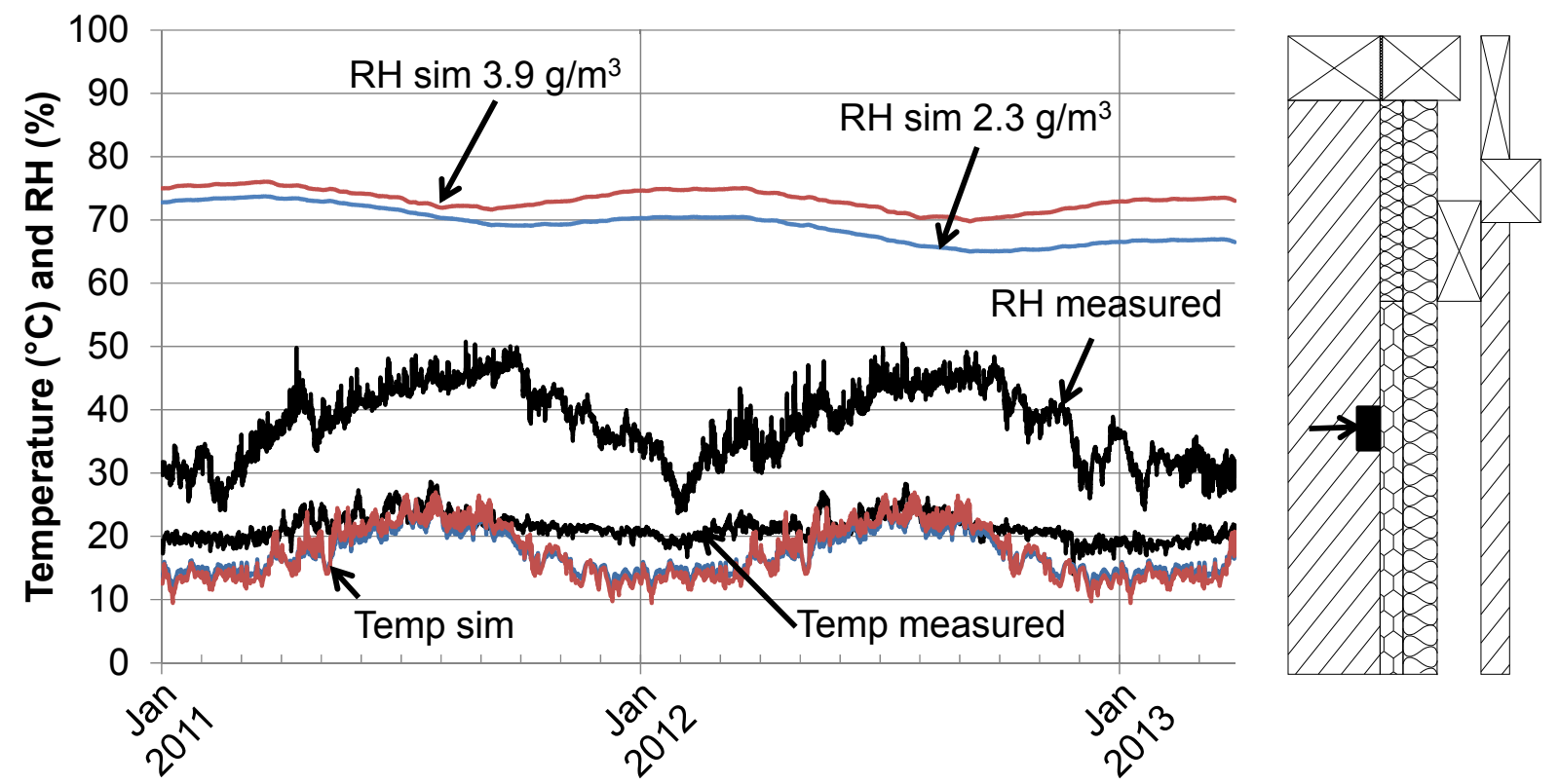

Figure 12. Comparison of the hygrothermal simulations with the measurements of the temperature and relative humidity behind the VIP in the wood wall. Two different indoor climates were simulated where the difference was in the level of indoor moisture excess. The location of the sensor is marked by the black box with a black arrow pointing from the left.

The simulations differed significantly from the measurements during the period 7 January, 2011 to 3 April, 2013 where the measured temperature was higher and the measured relative humidity was lower than in the simulations. The simulated temperature and relative humidity in the wall was on average $17.3^{\circ} \mathrm{C}$ and $73.2 \%$ for the high moisture excess and $17.4^{\circ} \mathrm{C}$ and $69.2 \%$ for the low moisture excess while the measured temperature and relative humidity was $21.3^{\circ} \mathrm{C}$ and $37.8 \%$ on average. The measured indoor temperature was $24.4^{\circ} \mathrm{C}$ which is $2.3-$ $3.4^{\circ} \mathrm{C}$ higher than what was used in the two simulated scenarios while the measured relative 
Preprint version, Energy and Buildings, Available online 21 January 2014

http://dx.doi.org/10.1016/j.enbuild.2014.01.019

humidity was $37.4 \%$ which is $11-15.6$ percentage points lower than in the simulations. The measured effective outdoor wall temperature was $9.2^{\circ} \mathrm{C}$ and the outdoor relative humidity was $75.1 \%$ which is 0.7 percentage points higher than the climate in the WUFI $2 \mathrm{D}$ database. The resulting measured moisture excess was $1.3 \mathrm{~g} / \mathrm{m}^{3}$, which is half to one third of the levels of moisture excess used in the simulations.

There are a number of factors that cause the large differences between the simulations and measurements. First of all, the climate used in the simulation differs from the measured climate, both indoors and outdoors. Since the wall is protected from rain by the wooden cover board and the air gap, the capillary moisture transfer through the wall is of no interest and only moisture diffusion through the wall is simulated. Also, the initial conditions were changed to a temperature of $20^{\circ} \mathrm{C}$ and $30 \%$ relative humidity to match the measured initial conditions in the wall. Figure 13 shows the results of the simulation using the measured indoor and outdoor climates in 2011 and 2012 compared to the measurements in the retrofitted wall.

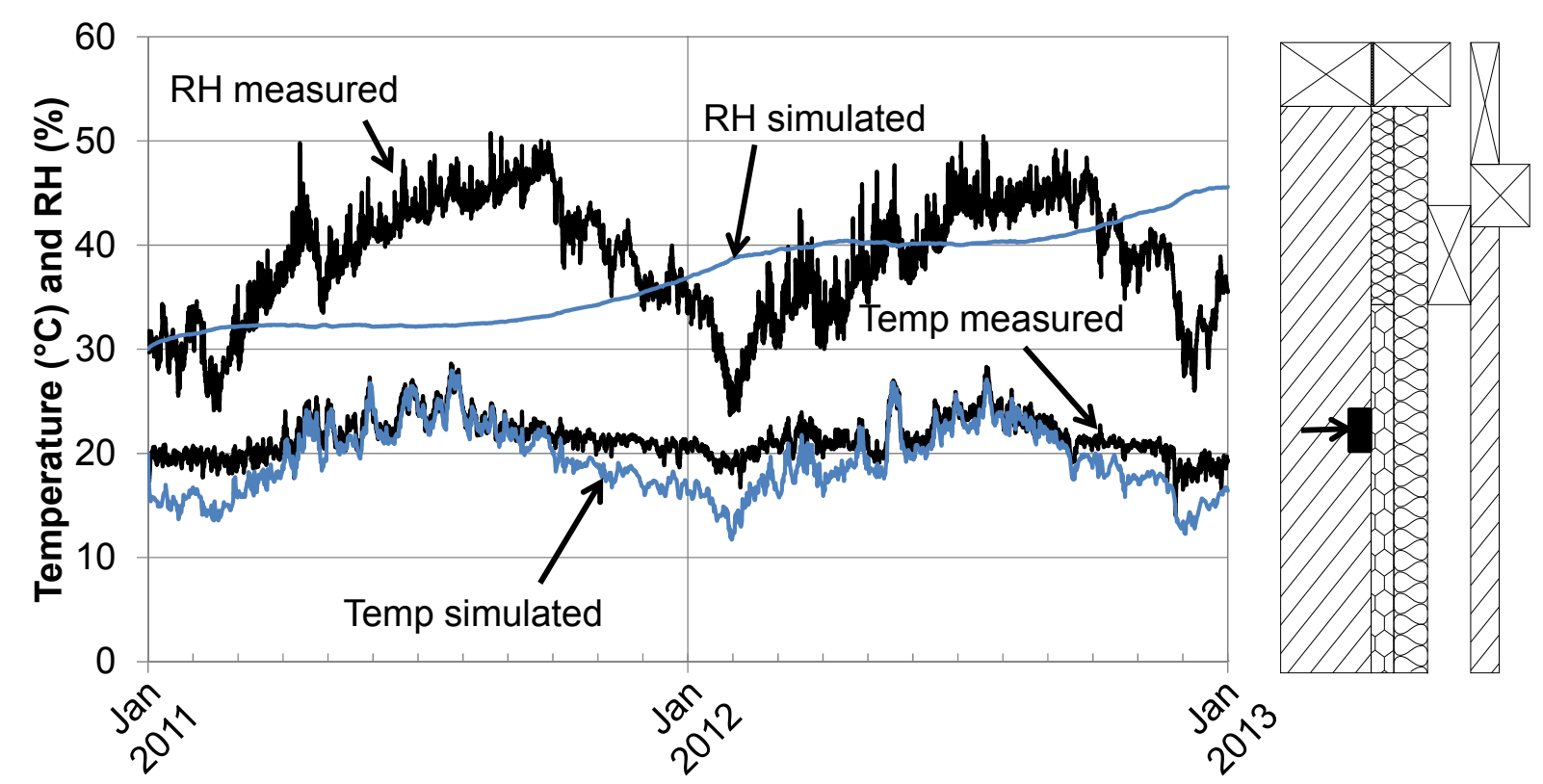

Figure 13. Comparison of the hygrothermal simulations with the measurements of the temperature and relative humidity behind the VIP in the wood wall. The simulation was based on the measured indoor and outdoor climate in 2011 and 2012. The location of the sensor is marked by the black box with a black arrow pointing from the left.

The accuracy of the simulation was, as expected, improved when simulating with the measured climate data and changed initial conditions. However, the measured temperature was still higher than what was simulated and the relative humidity increased over the two 
Preprint version, Energy and Buildings, Available online 21 January 2014

http://dx.doi.org/10.1016/j.enbuild.2014.01.019

years simulation with less variation than what the measurements showed. The average simulated temperature and relative humidity in the wall was $19.3^{\circ} \mathrm{C}$ and $36.9 \%$ while the measurements gave $21.5^{\circ} \mathrm{C}$ and $38.6 \%$. Therefore, there are other sources, except for the indoor and outdoor climates, causing the deviations. The vapor content was on average $1.2 \mathrm{~g} / \mathrm{m}^{3}$ higher in the simulations than from the measurements so there is an additional drying process in the wall which could be from air exchange with the dryer outdoor air. As described earlier, the sensor is located in an air filled void in the wood, measuring the temperature and relative humidity of the air closest to the sensor. The high fluctuation in the measured relative humidity indicates a leaky construction with air leakage from the interior or exterior side of the vapor barrier into the wood construction. In the real wall, air could enter e.g. through details around windows and be transported along the interior of the vapor barrier to the location of the sensor. The wall was designed to be as air tight as possible, but it is hard to make every connection and detail perfectly air tight. To match the simulated temperature and relative humidity with the measurements, an air exchange with the outdoor air was added to the model between the vapor barrier and wood, see Figure 14.

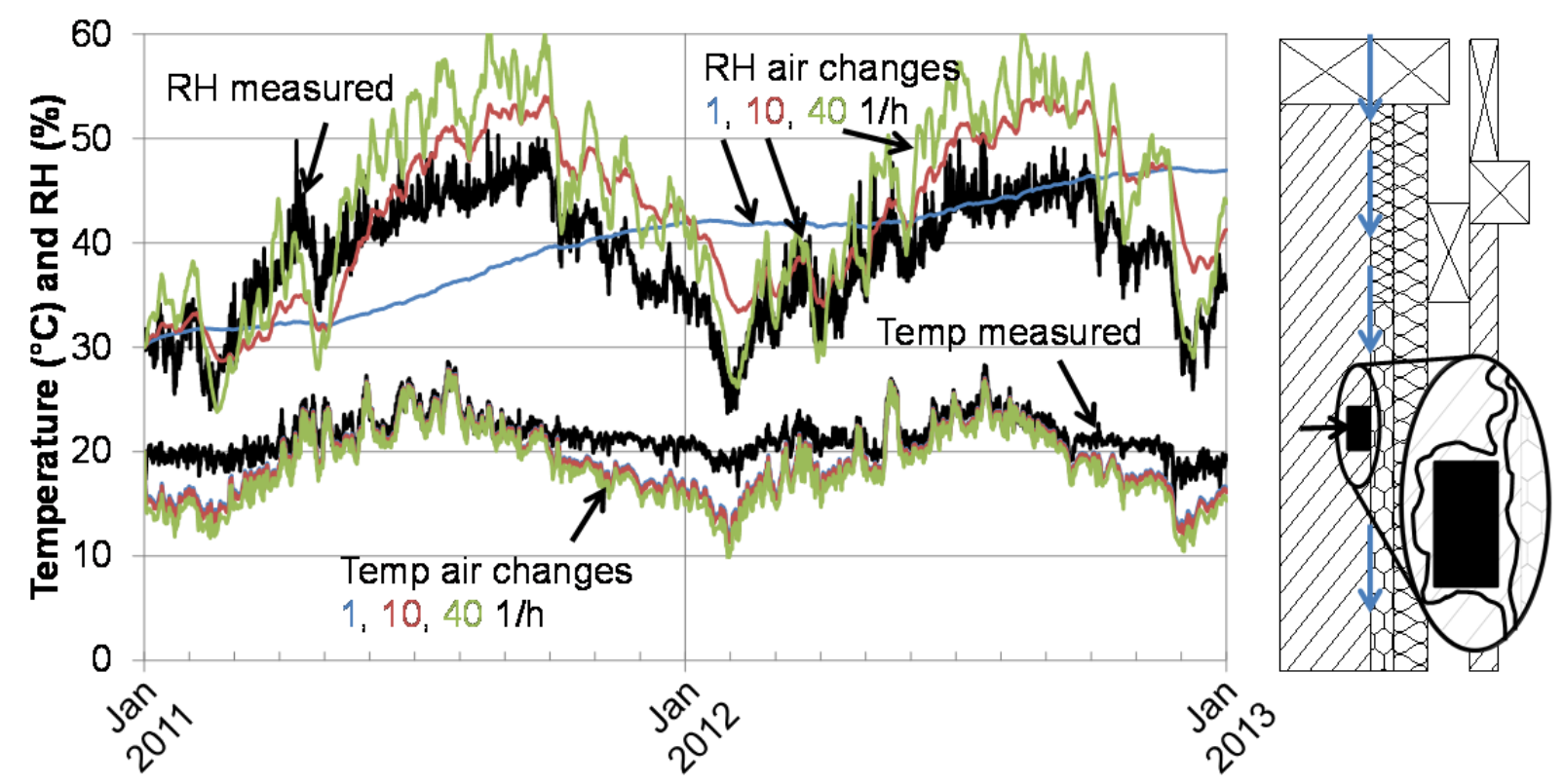

Figure 14. Comparison of the hygrothermal simulations with the measurements of the temperature and relative humidity behind the VIP in the wood wall. The air changes per hour with the outdoor air were varied from $11 / \mathrm{h}$ to $401 / \mathrm{h}$. The location of the sensor is marked by the black box with a black arrow pointing from the left. The material surfaces in the wall are not perfectly smooth which makes air flow through the small voids between them possible. 
Preprint version, Energy and Buildings, Available online 21 January 2014

http://dx.doi.org/10.1016/j.enbuild.2014.01.019

It is clear that the relative humidity in the wall fluctuates more with increasing air changes.

For 1 air changes per hour, the average relative humidity was $39.8 \%$, for $101 / \mathrm{h}$ it was $42.7 \%$ and for $40 \mathrm{1} / \mathrm{h}$ it was $43.9 \%$. The simulated average relative humidity is not increasing with time since the drying out capacity of the wall was increased with the air exchange. However, the temperature in the wall still differs from the measurements. The average simulated temperature was $19.3^{\circ} \mathrm{C}$ for 1 air changes per hour, $19.2^{\circ} \mathrm{C}$ for $101 / \mathrm{h}$ and $18.5^{\circ} \mathrm{C}$ for $40 \mathrm{1} / \mathrm{h}$ while the measured average temperature was $21.5^{\circ} \mathrm{C}$.

There are other parameter that could explain the difference between the measurements and simulations. The material properties of the wall could differ between the real case and the data available in the WUFI 2D database. Therefore the thermal conductivity of the air layer, glass wool and wood were changed in the simulations. The thermal conductivity of the air layer was changed from $0.18 \mathrm{~W} /(\mathrm{m} \cdot \mathrm{K})$ to the value for stagnant air which is $0.025 \mathrm{~W} /(\mathrm{m} \cdot \mathrm{K})$. The thermal conductivity of the glass wool was changed to $0.033 \mathrm{~W} /(\mathrm{m} \cdot \mathrm{K})$ instead of $0.04 \mathrm{~W} /(\mathrm{m} \cdot \mathrm{K})$ and the thermal conductivity of all the wood was changed to $0.2 \mathrm{~W} /(\mathrm{m} \cdot \mathrm{K})$ instead of $0.14 \mathrm{~W} /(\mathrm{m} \cdot \mathrm{K})$ in the longitudinal and $0.09 \mathrm{~W} /(\mathrm{m} \cdot \mathrm{K})$ in the radial direction. The simulated temperature and relative humidity in the wall dependent on the rate of air changes with the outdoor air is presented in Figure 15.

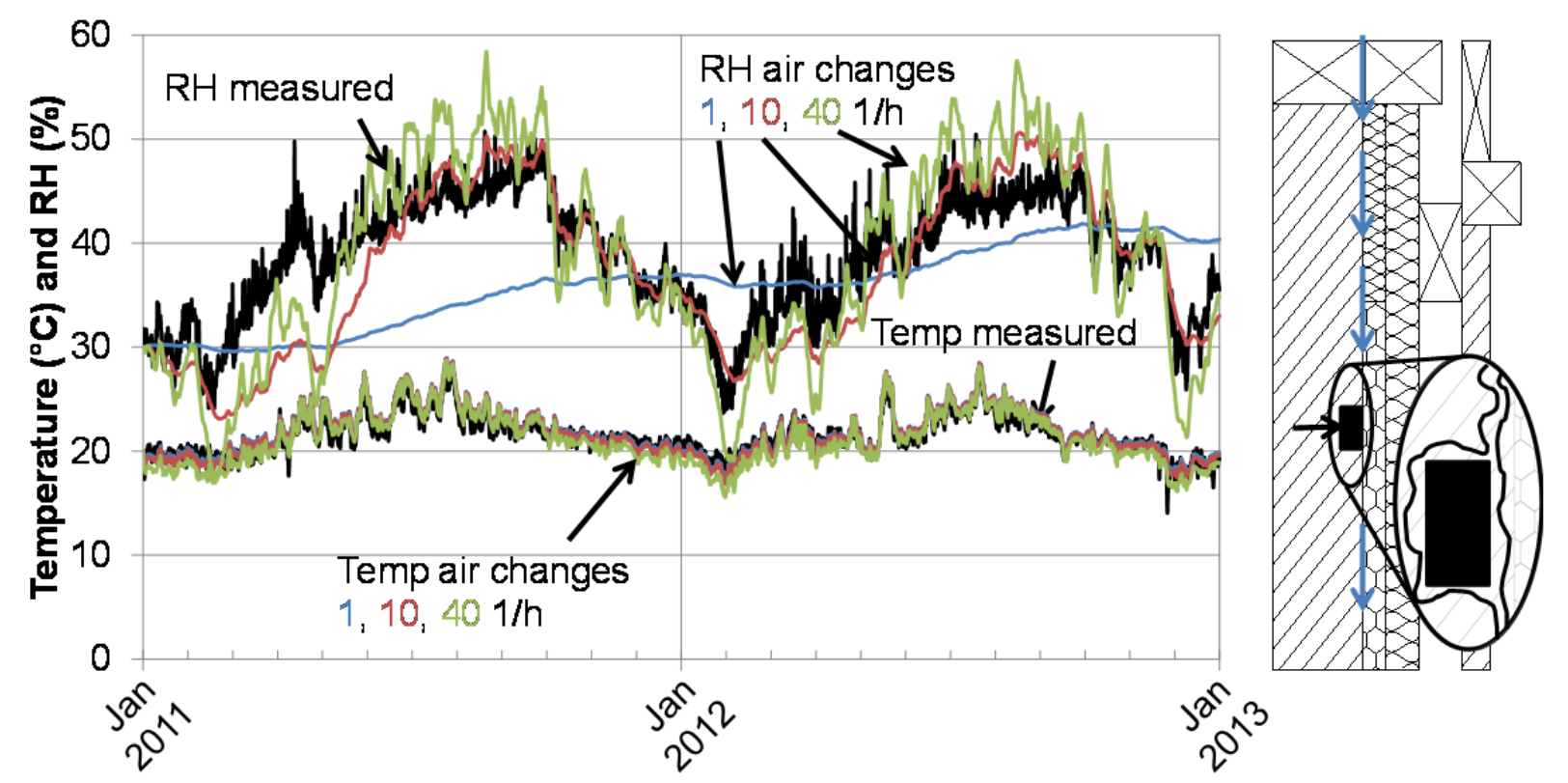

Figure 15. Comparison of the hygrothermal simulations with the measurements of the temperature and relative humidity behind the VIP in the wood wall. Simulations with a higher thermal conductivity of the air layer and glass wool and a lower thermal conductivity of the wood compared to the previous simulations. The air changes per hour with the outdoor air 
Preprint version, Energy and Buildings, Available online 21 January 2014

http://dx.doi.org/10.1016/j.enbuild.2014.01.019

were varied from $1 \mathrm{l} / \mathrm{h}$ to $40 \mathrm{l} / \mathrm{h}$. The location of the sensor is marked by the black box with a black arrow pointing from the left. The material surfaces in the wall are not perfectly smooth which makes air flow through the small voids between them possible.

With the additional changes to the model, the simulated temperature in the wall shows a substantially better agreement with the measurements. For 10 air changes per hour, the average temperature was $21.7^{\circ} \mathrm{C}$, for $201 / \mathrm{h}$ it was $21.5^{\circ} \mathrm{C}$, for $401 / \mathrm{h}$ and $100 \mathrm{1} / \mathrm{h}$ it was $21.2^{\circ} \mathrm{C}$. Also the average simulated relative humidity was in line with the measurements. For 10 air changes per hour, the average relative humidity was $37.4 \%$, for $201 / \mathrm{h}$ it was $37.6 \%$, for $40 \mathrm{1} / \mathrm{h}$ it was $38.3 \%$ and for $100 \mathrm{1} / \mathrm{h}$ it was $40.2 \%$. The measured relative humidity was $38.6 \%$ which corresponds well with the results of an air exchange rate of $401 / \mathrm{h}$. These results show the importance of knowing the correct material parameters and the air permeability of the construction. It is especially important when calculating the relative humidity in the construction which can be heavily influenced by the air exchange with the indoor or outdoor air.

\section{Conclusions}

In order to reduce the energy use in the existing building stock, retrofitting measures are needed. For listed buildings the exterior appearance and characteristics cannot be changed which limits the thickness of the additional insulation layer. With a substantially lower thermal conductivity than conventional insulation materials, VIP can be used to reduce the Uvalue of the wall with a thinner insulation layer. There are drawbacks when using VIP which requires good knowledge of how to work with the component in all stages of the construction project. The panels cannot be adapted on the construction site which requires a detailed design process where all panels are defined and preordered in the right size. If damages occur to the laminate around the VIP, the vacuum is lost and the thermal conductivity of the panel increases with a factor of five. It is not entirely clear how the dynamic conditions with varying temperature and relative humidity in the construction influences the service life of the panels. However, investigations have shown that only a minor part of the panels installed in a construction have a higher thermal conductivity than expected.

The thermal bridges created by the laminate around the VIP contribute to the increased heat flow through the wall. Also parts where VIP cannot be used, such as around windows, contributes to an increased heat flow. For old buildings, the dimensions of the construction are irregular which requires special investigations to make the retrofit successful. With a design 
Preprint version, Energy and Buildings, Available online 21 January 2014

http://dx.doi.org/10.1016/j.enbuild.2014.01.019

aiming to maximize the area where VIP is used, the retrofitting solution can be optimized by keeping the thermal bridges to a minimum.

It was found that air flow paths on the interior of the VIP could explain the higher fluctuations in the measured relative humidity compared to in the simulations. The air exchange with the outdoor air did not influence the temperature at the sensor position on the interior of the VIP. Knowledge of the air flow paths is crucial for making predictions of the long-term performance of a construction based on hygrothermal simulations.

External insulation in an old construction is an efficient mean to ensure a safe hygrothermal performance of the construction also in the future. However, care has to be taken to ensure the wall still has the possibility to dry out in case moisture penetrates the construction. VIP are not vapor permeable and therefore acts as a vapor barrier which could entrap moisture in the construction on the interior of the VIP. In this study it was proven that the VIP did not increase the moisture content in the wall after the retrofitting.

It is difficult to evaluate the performance of the VIP when installed in the wall. In the retrofitting solution presented here, the air space makes it impossible to identify the different panels by thermography. Only indirect methods, like the evaluation of the measured temperatures in the wall, can be used to follow the long-term performance of the panels. The only way to be certain that the panels in the wall are not damaged is to take the outer parts down to make the panels accessible for manual checking.

\section{Acknowledgements}

The work is supported by the Swedish Research Council for Environment, Agricultural Sciences and Spatial Planning (FORMAS) and the public housing corporation Familjebostäder i Göteborg AB. Thanks to Dr. Samuel Brunner at EMPA in Switzerland for a valuable discussion regarding the long-term durability predictions. Carl Molander and Måns Olofsson provided the energy simulation model developed in their Master's thesis project at Chalmers University of Technology.

\section{References}

[1] Naturvårdsverket, Miljömål, God bebyggd miljö, q-märkt (Environmental Objectives, A Good Built Environment, q mark). [In Swedish], http://www.miljomal.nu/, Accessed on 28 June, 2013. 
Preprint version, Energy and Buildings, Available online 21 January 2014

http://dx.doi.org/10.1016/j.enbuild.2014.01.019

[2] Boverket, Energi i bebyggelsen - tekniska egenskaper och beräkningar - resultat från projektet BETSI (Energy in the built environment - technical properties and calculations results from the BETSI study). [In Swedish], Boverket, Karlskrona, Sweden, 2010.

[3] H. Künzel, Effect of interior and exterior insulation on the hygrothermal behaviour of exposed walls, Materials and Structures, 31 (2) (1998) 99-103.

[4] M. Morelli, L. Rønby, S.E. Mikkelsen, M.G. Minzari, T. Kildemoes, H.M. Tommerup, Energy retrofitting of a typical old Danish multi-family building to a "nearly-zero" energy building based on experiences from a test apartment, Energy and Buildings, 54 (0) (2012) 395-406.

[5] B. Weller, S. Rexroth, S. Jakubetz, Denkmal und Energie - Technologien und Systeminnovationen zur Energieversorgung und -einsparung bei Baudenkmalen (Monuments and energy - Technologies and system innovations for energy supply and conservation in historical buildings). [In German], Technische Universität Dresden, Institut für Baukonstruktion, Dresden, Germany, 2008.

[6] P. Häupl, H. Fechner, H. Petzold, Interior Retrofit of Masonry Wall to Reduce Energy and Eliminate Moisture Damage: Comparison of Modeling and Field Performance, Proceedings of Thermal Performance of the Exterior Envelopes of Whole Buildings IX, Clearwater Beach, FL, USA, December 5-10, 2010.

[7] H. Johansson, Tilläggsisolering av tegelfasader på flerbostadshus från 1940- till 1960-talet (Brick facade refurbishments of buildings from the 1940s to 1960s). [In Swedish], Bachelor's Thesis, Luleå University of Technology, Department of Civil, Environmental and Natural resources engineering, Luleå, Sweden, 2011.

[8] C.-M. Capener, K. Sandin, M. Molnár, J. Jönsson, Energy efficient retrofitting of a 1950ies multi-dwelling block house considering hygrothermal properties - field measurements and simulation, Proceedings of 5th International Building Physics Conference, Kyoto, Japan, May 28-31, 2012.

[9] T.V. Rasmussen, Retrofitting Listed Buildings: Measures, Savings and Requirements, The Open Construction and Building Technology Journal, 5 (2011) (2011) 174-181.

[10] A. Binz, A. Moosmann, G. Steinke, U. Schonhardt, F. Fregnan, H. Simmler, S. Brunner, K. Ghazi, R. Bundi, U. Heinemann, H. Schwab, J.J.M. Cauberg, M.J. Tenpierik, G.A. Jóhannesson, T.I. Thorsell, M. Erb, B. Nussbaumer, Vacuum Insulation in the Building Sector. 
Preprint version, Energy and Buildings, Available online 21 January 2014

http://dx.doi.org/10.1016/j.enbuild.2014.01.019

Systems and Applications (Subtask B), IEA/ECBCS Annex 39 High Performance Thermal Insulation (HiPTI), 2005.

[11] K. Viridén, Retrofit Buildings close to Passive House Standard, Proceedings of International Conference Central Europe towards Sustainable Building CESB, Prague, Czech Republic, September 24-26, 2007.

[12] J. Dreyer, A. Korjenic, Investigation of the hygrical-thermal suitability of vacuum insulation boards for refurbishing of Viennese "Gründerzeit"-buildings, Proceedings of 7th International Vacuum Insulation Symposium, Duebendorf/Zurich, Switzerland, September 2829, 2005.

[13] L. Kubina, Etics with Integrated Vacuum Insulation Panels, Proceedings of International Conference Central Europe towards Sustainable Building CESB, Prague, Czech Republic, June 30-July 2, 2010.

[14] A. Binz, G. Steinke, Fassadendämmung mit Vakuum, applica, 113 (6) (2006) 22-30.

[15] M. Zwerger, H. Klein, Integration of VIP's into external wall insulation systems, Proceedings of 7th International Vacuum Insulation Symposium, Duebendorf/Zurich, Switzerland, September 28-29, 2005.

[16] U. Heinemann, R. Kastner, VIP-PROVE: Vakuumisolationspaneele - Bewährung in der Baupraxis. Wissenschaftliche Begleitforschung. Schlussbericht Energieoptimiertes Bauen, ViBau Report ZAE 2-1210-11 (2010) (VIP-PROVE: Vacuum insulation panels - Testing in construction practice. Scientific evaluation. Final report energy optimized construction). [In German], Bayerisches Zentrum für Angewandte Energieforschung e.V. ZAE Bayern, Würzburg, Germany, 2010.

[17] H. Schwab, J. Wachtel, H. Scheuerpflug, C. Stark, U. Heineman, H.-P. Ebert, J. Fricke, Entwicklung und Anwendung von evakuierten höchsteffizienten Dämmungen für Gebäude (Vakuumdämmung für Gebäude) Project Final Report ZAE 2-1203-21 (Development and use of evacuated highly efficient insulation for buildings (Vakuum insulation for buildings)). [In German], Bayerisches Zentrum für Angewandte Energieforschung e.V. ZAE Bayern, Würzburg, Germany, 2004.

[18] E. Sveipe, B.P. Jelle, E. Wegger, S. Uvsløkk, S. Grynning, J.V. Thue, B. Time, A. Gustavsen, Improving thermal insulation of timber frame walls by retrofitting with vacuum 
Preprint version, Energy and Buildings, Available online 21 January 2014

http://dx.doi.org/10.1016/j.enbuild.2014.01.019

insulation panels - experimental and theoretical investigations, J Build Phys, 35 (2) (2011) 168-188.

[19] R. Pfluger, W. Hasper, B. Schulze Darup, D. Sommer, M. Forstner, Wissenschaftlige Analyse eines auf vorgefertigten Vakuum-Paneel-Verbundplatten beruhenden Innendämmsystems. Abschlussbericht (Scientific analysis of an interior insulation system based on prefabricated vacuum insulation composite panels. Final report). [In German], VARIOTEC GmbH \& Co.KG, Neumarkt, Germany, 2008.

[20] P. Johansson, Assessment of the Risk for Mold Growth in a Wall Retrofitted with Vacuum Insulation Panels, Proceedings of 9th Nordic Symposium on Building Physics, Tampere, Finland, May 29-June 2, 2011.

[21] H. Simmler, S. Brunner, U. Heinemann, H. Schwab, K. Kumaran, P. Mukhopadhyaya, D. Quénard, H. Sallée, K. Noller, E. Kücükpinar-Niarchos, C. Stramm, M.J. Tenpierik, J.J.M. Cauberg, M. Erb, Vacuum Insulation Panels. Study on VIP-components and Panels for Service Life Prediction of VIP in Building Applications (Subtask A), IEA/ECBCS Annex 39 High Performance Thermal Insulation (HiPTI), 2005.

[22] H. Simmler, S. Brunner, Vacuum insulation panels for building application: Basic properties, aging mechanisms and service life, Energy and Buildings, 37 (11 SPEC. ISS.) (2005) 1122-1131.

[23] Prodexim, Fumed Silica, Prodexim UK Ltd., London, UK, http://www.prodexim.com/en/products/chemical/Fumed-Silica.html, Accessed on November 14, 2013.

[24] J. Fricke, Material research for the optimization of thermal insulations, High Temperatures - High Pressures, 25 (4) (1993) 379-390.

[25] H. Schwab, C. Stark, J. Wachtel, H.-P. Ebert, J. Fricke, Thermal Bridges in Vacuuminsulated Building Façades, Journal of Thermal Envelope \& Building Science, 28 (4) (2005) 345-355.

[26] M. Tenpierik, H. Cauberg, Analytical models for calculating thermal bridge effects caused by thin high barrier envelopes around vacuum insulation panels, Journal of Building Physics, 30 (3) (2007) 185-215.

[27] K. Ghazi Wakili, R. Bundi, B. Binder, Effective thermal conductivity of vacuum insulation panels, Build Res Inf, 32 (4) (2004) 293-299. 
Preprint version, Energy and Buildings, Available online 21 January 2014

http://dx.doi.org/10.1016/j.enbuild.2014.01.019

[28] K. Ghazi Wakili, T. Stahl, S. Brunner, Effective thermal conductivity of a staggered double layer of vacuum insulation panels, Energy and Buildings, 43 (6) (2011) 1241-1246.

[29] S. Brunner, T. Stahl, K. Ghazi Wakili, Single and double layered vacuum insulation panels of same thickness in comparison, Proceedings of Building Enclosure Science \& Technology (BEST) Conference, BEST 3: High Performance Buildings - Combining Field Experience with Innovation, Atlanta, GA, USA, April 2-4, 2012.

[30] Swedish Standards Institute, SS-EN 13165:2012. Thermal insulation products for buildings. Factory made rigid polyurethane foam (PU) products. Specification European Committee for Standardization (CEN), Brussels, Belgium, 2012.

[31] S. Brunner, H. Simmler, In situ performance assessment of vacuum insulation panels in a flat roof construction, Vacuum, 82 (7) (2008) 700-707.

[32] S. Brunner, Discussions on the long-term durability prediction of VIP. [E-mail correspondence, June, 2013 and November, 2013], Empa, Swiss Federal Laboratories for Materials Science and Technology, Dübendorf, Switzerland, 2013.

[33] S. Brunner, K. Ghazi Wakili, Hints for an additional aging factor regarding the thermal performance of vacuum insulation panels with pyrogenic silica core, Vacuum, 100 (0) (2014) 4-6.

[34] U. Larsson, G. Lönnroth, Landshövdingehus och trähus i Göteborg (County governor's houses and wooden houses in Gothenburg). [In Swedish], Den nordiske træstad, (28) (1972).

[35] T. Nilsson, Energideklaration för Kungsladugård 35:12, Göteborg (Energy certificate for Kungsladugård 35:12, Gothenburg). [In Swedish], Agera VVS-Design AB, Gothenburg, Sweden, 2009.

[36] C. Molander, M. Olofsson, Methods and Potentials to Reduce Peaks in Heating Power Demand - in Residential Building, Master's Thesis, Chalmers University of Technology, Department of Civil and Environmental Engineering, Gothenburg, Sweden, 2012.

[37] MathWorks, MATLAB, Vers. R2011b, The MathWorks, Inc., Natick, MA, USA, 2011.

[38] É. Mata, Energy efficiency and carbon dioxide mitigation in building stocks:

Development of methodology using the Swedish residential stock, Degree of Licentiate of Engineering, Chalmers University of Technology, Department of Energy and Environment, Gothenburg, Sweden, 2011. 
Preprint version, Energy and Buildings, Available online 21 January 2014

http://dx.doi.org/10.1016/j.enbuild.2014.01.019

[39] GE Sensing, Protimeter HygroTrac Remote Wireless Monitoring System: Instruction Manual, GE Sensing, Billerica, MA, USA, 2007.

[40] C. Hoogenboom, Discussion on the causes for missing data. [E-mail Henrik Karlsson (SP Technical Research Institute of Sweden), 14 August, 2012], OmniSense LLC, Ladys Island, SC, USA, 2012.

[41] P. Johansson, Retrofitting of old Exterior Wall with Vacuum Insulation Panels: Meaurements of Thermal Properties, Moisture Performance and Practical Considerations, Degree of Licentiate of Engineering, 2012:2, Chalmers University of Technology, Department of Civil and Environmental Engineering, Gothenburg, Sweden, 2012.

[42] B.-Å. Petersson, Byggnaders klimatskärm: fuktsäkerhet, energieffektivitet, beständighet (Building Envelope: moisture safety, energy efficiency and durability). [In Swedish], Studentlitteratur, Lund, Sweden, 2009.

[43] Fraunhofer IBP, WUFI 2D Transient Heat and Moisture Transport, Vers. 3.3.2, Fraunhofer IBP, Holzkirchen, Germany, 2010. 